\title{
ESTUDO DE ALGUMAS CARACTERÍSTICAS AGRONÔMICAS DE Panicum maximum (Jacq.) CVS. TANZÂNIA E MOMBAÇA PARA ESTABELECER SEU MANEJO
}

\section{PATRICIA MENEZES SANTOS}

Engenheira Agrônoma

Orientador: Prof. Dr. MOACYR CORSI

Dissertação apresentada à Escola Superior de Agricultura "Luiz de Queiroz", Universidade de São Paulo, para obtenção do título de Mestre em Agronomia, Área de Concentração: Ciência Animal e Pastagens.

P I R A C I C A B A

Estado de São Paulo - Brasil

Outubro - 1997 
Dados Internacionais de Catalogaçāo na Publicaçāo (CIP)

DIVISÃO DE BIBLIOTECA E DOCUMENTAÇĀO - Campus "Luiz de Queiroz"/USP

\section{Santos, Patricia Menezes}

Estudo de algumas caracteristicas agronômicas de Panicum maximum (Jacq.) cvs. Tanzânia e Mombaça para estabelecer seu manejo / Patricia Menezes Santos. - Piracicaba, 1997.

$$
62 \mathrm{p} \text {. }
$$

Dissertaçāo (mestrado) - - Escola Superior de Agricultura Luiz de Queiroz, 1997. Bibliografia.

1. Capim coloniāo 2. Caracteristica agronômica 3. Graninea forrageira 4. Manejo 5. Pastagem I. Título 
ESTUDO DE ALGUMAS CARACTERÍSTICAS AGRONÔMICAS DE Panicum maximum (Jacq.) CVS. TANZÂNIA E MOMBAÇA PARA ESTABELECER SEU MANEJO

\section{PATRICIA MENEZES SANTOS}

Aprovada em: 20.11.1997

Comissão julgadora:

Prof. Dr. Moacyr Corsi

ESALQ/USP

Prof. Dr. Luiz Roberto de Andrade Rodrigues

FMVAJ/UNESP

Dr. Carlos Guilherme Silveira Pedreira

ESALQ/USP

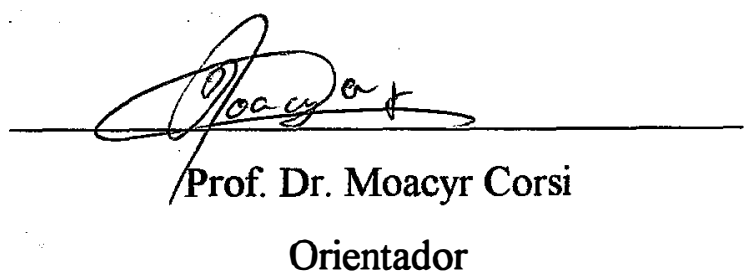


Aos meus pais,

Maria Amélia e Roberto,

por sua dedicação e carinho

Dedico. 


\section{AGRADECIMENTOS}

- Ao Prof. Dr. Moacyr Corsi, pela contribuição para a minha formação e pela orientação na condução deste trabalho.

- Ao Eng. Agr. Marco Antônio Alvares Balsalobre, pela ajuda, incentivo e paciência, principalmente nos momentos mais dificeis da condução deste trabalho.

- Ao Prof. Dr. Vidal Pedroso de Faria, pela contribuição para a minha formação.

- Ao Prof. Dr. Sila Carneiro da Silva, pela ajuda na elaboração deste trabalho.

- Ao meu irmão, Roberto Figueira Santos Filho, pelo incentivo e pela preciosa colaboração no processamento dos dados deste experimento.

- Aos meus irmãos, Anneliese, Cristiana, Edgard e Maria Carmen, pelo incentivo para a realização deste trabalho.

- Aos estagiário, Fuad Samir Cury e Marcos Ribeiro, pela ajuda na condução do experimento.

- Aos estagiários do CPZ, principalmente Jalme de Souza Fernandes Júnior, pela ajuda na condução do experimento.

- Ao técnico do Laboratório de Bromatologia da ESALQ-USP, Carlos César Alves.

- Ao funcionário do Departamento de Zootecnia da ESALQ-USP, Laureano.

- Ao Sr. José Carlos Maschietto, da Sementes J. C. Maschietto, por ter fornecido as sementes para a implantação da área experimental. 
SUMÁRIO

Página

LISTA DE FIGURAS ................................................................ vi

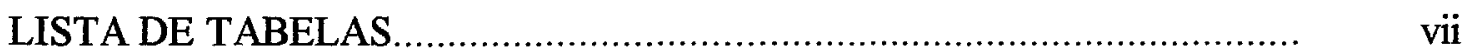

RESUMO

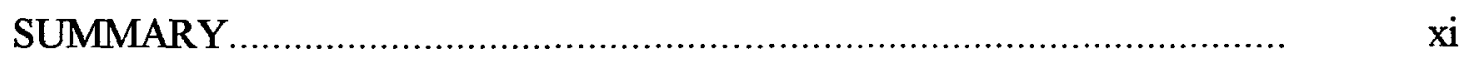

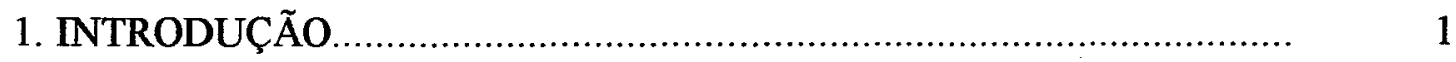

2. REVISÃO DE LITERATURA

2.1. Os cultivares Tanzânia e Mombaça..................................................... 3

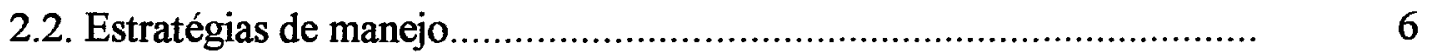

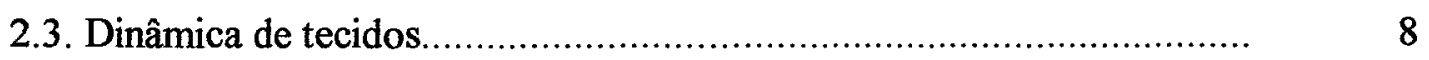

3. MATERIAL E MÉTODOS .............................................................. 21

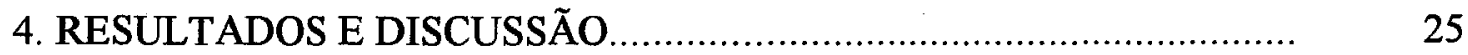

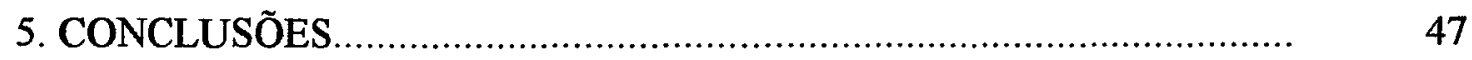

6. REFERÊNCIAS BIBLIOGRÁFICAS ................................................ 48 


\section{LISTA DE FIGURAS}

Página

1 Precipitação $(\mathrm{mm})$ e temperatura média mensal $\left({ }^{\circ} \mathrm{C}\right)$ de outubro de 1995 a outubro de 1996.

2 Taxa de acúmulo líquido e de senescência entre novembro de 1995 e abril de 1996 (estádio vegetativo) para a) capim Mombaça e b) capim Tanzânia......

3 Taxa de acúmulo líquido e de senescência em abril/maio (estádio reprodutivo) para a) capim Mombaça e b) capim Tanzânia..

4 Taxa de acúmulo líquido em maio/setembro (estádio vegetativo) em a) capim Mombaça e b) capim Tanzânia. 


\section{LISTA DE TABELAS}

Página

1 Diferenças morfológicas entre os capins Tanzânia, Mombaça, Tobiatã e Colonião.

2 Efeito do intervalo entre pastejos e do período de avaliação sobre a taxa de alongamento foliar ( $\mathrm{cm} /$ dia.perfilho) e das hastes $(\mathrm{cm} /$ dia.perfilho) no capim Mombaça.....

3 Efeito do intervalo entre pastejos e do período de avaliação sobre a taxa de alongamento foliar ( $\mathrm{cm} /$ dia.perfilho) e das hastes $(\mathrm{cm} /$ dia.perfilho) no capim Tanzânia.

4 Efeito do intervalo entre pastejos sobre a taxa de senescência (cm/dia.perfilho) nos capins Mombaça e Tanzânia.

5 Efeito do período sobre a taxa de senescência ( $\mathrm{cm} /$ dia.perfilho) nos capins Mombaça e Tanzânia.

6 Efeito do período sobre a densidade populacional de perfilhos (perfilhos $/ \mathrm{m}^{2}$ ) nos capins Mombaça e Tanzânia.

7 Efeito do intervalo entre pastejos e do período de avaliação sobre a altura do pasto (cm) nos capins Mombaça e Tanzânia.

8 Efeito do intervalo entre pastejos e do período de avaliação sobre o comprimento das hastes $(\mathrm{cm})$ no capim Mombaça.

9 Efeito do intervalo entre pastejos e do período de avaliação sobre o comprimento das hastes $(\mathrm{cm})$ no capim Tanzânia

10 Efeito do intervalo entre pastejos e do período na relação folha:haste do capim Tanzânia.

11 Efeito do intervalo entre pastejos sobre a relação folha:haste do capim Mombaça

12 Efeito do período do ano sobre a relação folha:haste do capim Mombaça... 
13 Efeito do intervalo entre pastejos e do período de avaliação sobre o comprimento total de folhas verdes $(\mathrm{cm})$ no capim Mombaça ..........................

14 Efeito do intervalo entre pastejos e do período de avaliação sobre o comprimento total de folhas verdes $(\mathrm{cm})$ no capim Tanzânia

15 Efeito do intervalo entre pastejos e do periodo de avaliação sobre o número de folhas vivas no capim Mombaça

16 Efeito do intervalo entre pastejos e do período de avaliação sobre o número de folhas vivas no capim Tanzânia. 


\title{
ESTUDO DE ALGUMAS CARACTERÍSTICAS AGRONÔMICAS DE Panicum maximum (Jacq.) CVS. TANZÂNIA E MOMBAÇA PARA ESTABELECER SEU MANEJO
}

\author{
Autora: PATRICIA MENEZES SANTOS \\ Orientador: Prof. Dr. MOACYR CORSI
}

\section{RESUMO}

Nos últimos anos, têm sido lançados vários cultivares de Panicum maximum, porém pouco se sabe, ainda, a respeito de suas exigências quanto ao manejo. $O$ presente trabalho teve por objetivo avaliar algumas características dos cultivares Tanzânia e Mombaça, submetidos a três intervalos entre pastejos ao longo de um ano.

Os experimentos foram conduzido em área do Departamento de Zootecnia da ESALQ-USP ( $\left(22^{\circ} 42^{\prime} 30^{\prime \prime} \mathrm{S}\right.$ e $\left.47^{\circ} 38^{\prime} 30^{\prime \prime} \mathrm{W}\right)$, no período de outubro de 1995 a outubro de 1996. O delineamento experimental foi de blocos completos ao acaso com parcelas subdivididas no tempo. Havia sete repetições para cada tratamento. Para cada cultivar, foi testado o efeito de três intervalos entre pastejos $(28,38$ e 48 dias) e de sete períodos $(14 / 11 / 1995$ a $31 / 12 / 1995,1 / 1 / 1996$ a 17/2/1996, 18/2/1996 a 5/4/1996, 6/4/1996 a 23/5/1996, 24/5/1996 a 10/7/1996, 11/7/1996 a 27/8/1996 e 28/8/1996 a 14/9/1996). A análise de variância foi aplicada aos efeitos dos intervalos entre pastejos, dos periodos do ano e da interação entre os dois. As médias foram comparadas pelo teste " $t$ ".

$O$ resíduo pós pastejo foi em média $2.300 \mathrm{~kg} /$ ha para o Mombaça e $1.900 \mathrm{~kg} / \mathrm{ha}$ para o Tanzânia. As adubações se repetiram sempre após a saída dos animais. Todas as parcelas 
receberam $400 \mathrm{~kg} /$ ha de nitrogênio na forma de uréia durante o verão, divididos em 6,5 e 4 aplicações para 28, 38 e 48 dias de intervalo entre pastejos, respectivamente.

Avaliaram-se as seguintes características: taxa de alongamento foliar, taxa de alongamento das hastes, taxa de senescência, número de folhas vivas por perfilho, comprimento total de folhas verdes por perfilho, comprimento das hastes, densidade populacional de perfilhos, altura do pasto e relação folha:haste da forragem. Essas informações permitiram determinar a taxa líquida de acúmulo de matéria seca, expressa como porcentagem da máxima taxa de acúmulo total.

Os resultados do presente experimento indicam que o Mombaça deve ser pastejado com menos de 28 dias de intervalo no período de novembro a maio e com mais de 48 dias entre maio e setembro. Já o Tanzânia deve ser pastejado com menos de 38 dias entre novembro e abril, com menos de 28 durante a fase reprodutiva e com mais de 48 entre maio e setembro. A extensão dos períodos de descanso pode reduzir a eficiência do sistema, porém ainda continuará havendo acúmulo líquido de forragem. Esta verificação importa, sobretudo, aos sistemas de manejo menos intensivos, onde o controle do intervalo entre pastejos é menos rigoroso.

São necessários mais estudos sobre a interação entre: altura das plantas na pastagem e perdas físicas de forragem; altura das hastes e comportamento de pastejo dos animais; relação folha:haste e valor alimentar da forragem, levando-se em consideração a pressão de pastejo e o resíduo pós-pastejo.

O uso do filocrono no manejo de pastagens ainda apresenta muitas limitações, principalmente devido à variabilidade na população de perfilhos que constituem o pasto. Sugere-se determinar qual a categoria de perfilhos responsável pela maior parte da produção e basear o manejo no comportamento desta. 


\title{
A STUDY OF CHARACTERISTICS OF Panicum maximum (Jacq.) CVS. TANZÂNIA E MOMBAÇA TO ESTABLISH THEIR MANAGEMENT
}

\author{
Author: PATRICIA MENEZES SANTOS \\ Adviser: Prof. Dr. MOACYR CORSI
}

SUMMARY

Two experiments were made in Piracicaba-SP-Brazil $\left(22^{\circ} 42^{\prime} 30^{\prime \prime} \mathrm{S}\right.$ and $47^{\circ} 38^{\prime} 30^{\prime \prime} \mathrm{W}$ ), between 1995 and 1996 , to evaluate the effects of three grazing intervals (28, 38 and 48 days) within seven periods of time (11/14/1995 to $12 / 31 / 1995,1 / 1 / 1996$ to $2 / 17 / 1996,2 / 18 / 1996$ to $4 / 5 / 1996,4 / 6 / 1996$ to $5 / 23 / 1996,5 / 24 / 1996$ to $7 / 10 / 1996$, $11 / 7 / 1996$ to $8 / 27 / 1996$ and $8 / 28 / 1996$ to $9 / 14 / 1996$ ) on some characteristics of Panicum maximum cvs. Tanzânia and Mombaça. The trials were assigned in a split plot experimental design, with harvesting intervals as main plots and periods as subplots.

Mean residual herbage was $2.300 \mathrm{~kg} / \mathrm{ha}$ for Mombaça and $1.900 \mathrm{~kg} / \mathrm{ha}$ for Tanzânia. All plots received $400 \mathrm{~kg} / \mathrm{ha}$ of $\mathrm{N}$ during the summer.

Leaf elongation rate, stem elongation rate, senescence rate, net herbage accumulation rate, number of live leaves per tiller, leaves length, stem length, tillers population density, pasture height and leaf:stem ratio were determined.

It was concluded that grazing intervals for Mombaça should be less than 28 days between November and May (late spring, summer and early autumn) and more than 48 days between May and September (late autumn and winter). Grazing intervals for Tanzânia should be shorter than 38 days between November and April (late spring and 
summer), shorter than 28 days during reproductive stage (autumn) and longer than 48 days between May and September (winter). Extended grazing intervals will decrease efficiency, but there will still be forage accumulation. This information is important for systems where the control over harvesting intervals is not very rigorous.

More information is necessary about: the effects of pasture height on losses; the effects of stem height on animals behaviour; and the effects of leaf:stem ratio on herbage quality.

The use of phyllochron on pasture management has many limitations, due to tillers variability. It is suggested that another group of experiments be done to determine the class of tiller responsible for most of the production and use their behaviour to establish the management. 


\section{1) INTRODUÇÃO}

Apesar do elevado potencial de produção do capim Colonião (Panicum maximum, Jacq.), a insatisfação dos pecuaristas com os niveis de produtividade alcançados e com o ritmo de degradação de suas pastagens fez com que este passasse a ser substituído, principalmente pelas braquiárias (Brachiaria spp.), a partir da década de 60.0 insucesso dos pecuaristas no cultivo e manutenção de pastagens de capim Colonião, no entanto, não era devido à espécie em si, mas ao mau manejo e aos baixos índices de fertilidade do solo.

Nos últimos anos, as instituições de pesquisa têm lançado uma série de novos cultivares de Panicum maximum (Jacq.), mas pouco tem sido feito para determinar o manejo destes capins, o que pode levar ao fracasso dos mesmos nas áreas comerciais.

Na realidade, foi criado um ciclo vicioso, onde a insatisfação dos pecuaristas com o desempenho dos pastos em suas propriedades os leva a buscar novos capins. Em resposta a essa pressão, as instituições de pesquisa se precipitam lançando novas espécies e variedades, sem que tenha havido tempo para determinar as suas exigências.

São necessários estudos sobre princípios básicos que expliquem como a produção e a utilização de pastagens são afetadas pelo manejo, tornando possivel estabelecer bases para comparar sistemas e identificar formas de contornar suas limitações.

Neste trabalho, estudou-se o comportamento de dois cultivares de $P$. maximum (Jacq.), Tanzânia e Mombaça, submetidos a três intervalos entre pastejos 
$(28,38,48$ dias) ao longo de um ano. Para isso, foram avaliados, entre outros, a dinâmica de tecidos, a relação folha:haste e a altura da planta. 


\section{2) REVISÃO DE LITERATURA}

\section{1) Os cultivares Tanzânia e Mombaça}

Os capins Tanzânia (BRA-007218) e Mombaça (BRA-006645) foram coletados pelo ORSTOM (Institut Français de Recherche Scientifique pour le Développement en Coopération) em Korogwe, na Tanzânia. O lançamento comercial destes capins em 1990 e 1993, respectivamente, foi fruto de um longo trabalho de seleção coordenado pela EMBRAPA (Jank et al., 1994; Jank, 1995).

O capim Mombaça "é uma planta cespitosa com altura média de 1,65 m. As folhas são quebradiças, com largura média de $3,0 \mathrm{~cm}$ e sem cerosidade. As lâminas apresentam poucos pêlos, duros e curtos, principalmente na face superior. As bainhas são glabras. Os colmos são levemente arroxeados. A inflorescência é uma panícula com ramificações primárias longas e secundárias longas apenas na base. As espiguetas são glabras, uniformemente distribuídas, e arroxeadas em aproximadamente $1 / 3$ da superfície externa. O vertículo normalmente apresenta micropilosidade" (Savidan et al., 1990).

O capim Tanzânia "é uma planta cespitosa com altura média de $1,3 \mathrm{~m}$ e folhas decumbentes com largura média de $2,6 \mathrm{~cm}$. Lâminas e bainhas são glabras, sem cerosidade. Os colmos são levemente arroxeados. As inflorescências são do tipo panícula, com ramificações primárias longas, e secundárias longas apenas na base. As espiguetas são arroxeadas, glabras e uniformemente distribuídas. O vertículo é glabro" (Savidan et al., 1990). 
A Tabela 1 mostra de forma simplificada as principais diferenças morfológicas entre os capins Tanzânia, Mombaça, Colonião e Tobiatã.

Tabela 1: Diferenças morfológicas entre os capins Tanzânia, Mombaça, Tobiatã e Colonião.

\begin{tabular}{lcccc}
\hline \multicolumn{1}{c}{ Variável } & \multicolumn{4}{c}{ Dados morfológicos } \\
\cline { 2 - 5 } & Tanzânia & Mombaça & Tobiatã & Colonião \\
\hline Altura da planta (m) & 1,2 & 1,7 & 1,6 & 1,4 \\
Largura das folhas (cm) & 2,7 & 3,0 & 4,6 & 2,9 \\
Manchas roxas nas espiguetas & muitas & poucas & muitas & média \\
Pilosidade nas folhas & ausente & pouca & pouca & ausente \\
Pilosidade nos colmos & ausente & ausente & muita & ausente \\
Cerosidade nos colmos & ausente & ausente & ausente & presente \\
Porte das folhas & decumbentes & eretas & eretas & eretas \\
\hline
\end{tabular}

Fonte: Jank (1995).

O potencial de utilização destes capins pode ser verificado através dos resultados obtidos durante a avaliação dos acessos no CNPGC (Centro Nacional de Pesquisa em Gado de Corte - EMBRAPA). O capim Mombaça produziu 41 t/ha.ano de matéria seca total, sendo $33 \mathrm{t} /$ ha.ano de matéria seca foliar (81,9\%) e apresentou em média $13,4 \%$ de proteína bruta nas folhas e 9,7\% nos colmos. Já o capim Tanzânia produziu 33 t/ha.ano de matéria seca total, sendo 26 t/ha.ano de matéria seca foliar $(80 \%)$ e teve em média $12,7 \%$ de proteína bruta nas folhas e $9 \%$ nos colmos (Jank et al., 1994; Jank, 1995; Savidan et al., 1990).

Esses resultados, no entanto, não podem ser adotados como regra geral. Em uma avaliação feita na Amazônia Oriental por Dias Filho et al. (1995), o capim Tanzânia foi classificado no grupo dos cultivares que melhor se adaptaram à região e o capim Mombaça no pior. Esses autores explicam que, apesar do capim Mombaça ter 
apresentado uma produção de matéria seca e relação folha:haste adequadas, seu baixo vigor, baixa capacidade de cobertura do solo, alta susceptibilidade a doenças e a apresentação de sintomas de deficiência nutricional fizeram com que fosse considerado inadequado para a região.

Esse trabalho deixa claro que, apesar de pertencerem à mesma espécie, esses capins apresentam respostas diferentes às variações impostas pelo meio e pelo sistema de produção adotado. Para Jank (1995), devido às suas características, o capim Mombaça terá êxito em sistemas intensivos de produção, já o capim Tanzânia é menos exigente em termos de manejo.

No experimento conduzido por Cecato et al. (1996) os cortes eram feitos a cada 35 dias no verão e 70 no inverno. A produção por corte no verão foi de 7.186 e 7.441 $\mathrm{kg} / \mathrm{ha}$ e no inverno de 2.483 e $2.711 \mathrm{~kg} / \mathrm{ha}$, para os capim Mombaça e Tanzânia, respectivamente. Isso mostra a acentuada estacionalidade de produção destes cultivares.

Uma das características de produção que é afetada ao longo do ano é o perfilhamento. Barbosa et al. (1996) observaram que na primavera a maior parte dos perfilhos novos aparecia na primeira semana após o corte, enquanto nas demais épocas do ano o perfilhamento se estendia até a terceira semana, tanto para o capim Tanzânia quanto para o capim Mombaça. Os autores observaram também que na rebrota do capim Tanzânia havia maior número de perfilhos remanescentes que novos, enquanto para o capim Mombaça não houve diferença. No entanto, o peso dos perfilhos não foi avaliado, ou seja, não se sabe se os perfilhos mais tardios realmente contribuem para a produção do pasto e nem qual a real participação de perfilhos novos e remanescentes na rebrota dos capins.

Por terem sido lançados recentemente, as informações sobre os capim Tanzânia e Mombaça ainda são muito escassas e a maior parte dos dados publicados é proveniente de ensaios de avaliação dos cultivares. A determinação mais cuidadosa das exigências quanto ao manejo e à fertilidade de solo é fundamental no sentido de evitar que esses cultivares sejam prejudicados devido ao uso inadequado. 


\section{2) Estratégias de manejo}

Até pouco tempo atrás, o objetivo no manejo de pastagens era permitir que a planta tivesse uma rebrota vigorosa e elevada produção. Isso levou à realização de uma série de trabalhos relacionados ao índice de área foliar, à reserva de carboidratos solúveis, à área foliar remanescente, à preservação de meristema apical, etc. No entanto, elevadas produções da planta forrageira nem sempre se refletem em alta produção animal (Corsi et al., 1994).

Parsons et al. (1983) estudaram a influência da intensidade de pastejo sobre o fluxo de carbono em uma pastagem de azevém perene (Lolium perenne), e até que ponto os produtos da fotossíntese eram colhidos pelos animais. Esses autores concluíram que a taxa bruta de fotossíntese e produção de parte aérea foram maiores no pastejo leniente, porém o consumo foi maior no pastejo mais severo, onde as perdas por senescência foram menores.

Essa linha de pesquisa mostrou que o importante é maximizar a quantidade de material colhido na área, o que deve ser conseguido em situações intermediárias, onde nem a produção nem a eficiência de colheita são máximas (Hodgson, 1990).

Para o pastejo rotacionado, tem-se considerado que o melhor balanço entre fotossíntese, produção e senescência é obtido quando a forragem é colhida ao atingir a máxima taxa de acúmulo líquido. É importante lembrar, no entanto, que o animal tem que ser capaz de colher esta forragem, ou seja, em situações onde a taxa de acúmulo se mantém elevada, mas a presença de hastes começa a limitar o consumo de forragem, o manejo deve ser direcionado para a resolução deste problema (Parsons \& Penning, 1988).

A intensidade de desfolha adotada interfere de forma marcante na resposta do pasto. Em situações onde o resíduo pós-pastejo é baixo, a taxa de acúmulo líquido aumenta rapidamente até atingir um máximo, quando se torna relativamente insensivel ao tempo de rebrota. À medida que se diminui a intensidade de desfolha, o tempo para atingir a máxima taxa de acúmulo líquido torna-se menor. Resíduos muito elevados 
prejudicam a rebrota., fazendo com que a taxa de acúmulo líquido seja menor e decresça com o tempo (Parsons et al., 1988).

Grant et al. (1981) avaliaram a resposta do azevém perene submetido a diferentes pressões de pastejo e alturas de cortes, e observaram que após um período de quatro semanas de rebrota a taxa de acúmulo líquido de forragem era semelhante em todos os tratamentos. Pouco depois, os trabalhos conduzidos por Grant et al. (1983), Bircham \& Hodgson (1983) e King et al. (1984) com plantas temperadas sob pastejo contínuo mostraram que, dentro de uma certa faixa de altura, disponibilidade de forragem e indice de área foliar (IAF), as variações na taxa líquida de produção do pasto eram pequenas. Esses resultados foram atribuídos a uma série de mecanismos de compensação da planta forrageira que envolvem mudạnças na densidade populacional de perfilhos e no balanço entre taxa de crescimento e de senescência.

Esses experimentos reforçam a necessidade de se estudar os mecanismos que controlam crescimento, consumo e senescência numa pastagem, assim como as suas interações e as suas respostas aos fatores do meio e de manejo (Hodgson, 1990).

$O$ crescimento e a senescência em pastagens podem ser estudados através da: taxa de aparecimento e de alongamento e longevidade das folhas. Quando sob condições adequadas de crescimento, o número de folhas que uma gramínea consegue manter por perfilho parece ser relativamente constante, sendo que o aparecimento de uma nova folha coincide com a morte da mais velha. Logo após uma desfolha severa, não há senescência e a taxa de acúmulo de forragem corresponde à assimilação líquida. Depois de algum tempo, as primeiras folhas produzidas começam a morrer, mas como estas são de menor tamanho, o crescimento ainda é maior que a senescência. Nesta fase, a taxa de acúmulo líquido de forragem é máxima. A partir daí, a taxa de senescência aumenta, até que se torna igual ao crescimento (Holmes, 1994; Hodgson, 1990; Lemaire \& Chapman, 1996).

Quando a folha não é colhida em um determinado espaço de tempo, ela inevitavelmente morre. Desta forma, para maximizar a eficiência de utilização da forragem produzida, é necessário conhecer o tempo de vida das folhas, e os intervalos de 
desfolha devem ser determinados de tal forma que a maior parte das folhas tenha chance de ser colhida pelo menos uma vez. Foi com base nestes princípios que Fulkerson $\&$ Slack (1994) e Fulkerson \& Slack (1995) elaboraram um estudo com azevém perene onde se confirmou que, para esta espécie, o ideal é a desfolha no estádio de três folhas expandidas.

\section{3) Dinâmica de tecidos}

O fluxo de matéria seca em um pasto pode ser estudado através das taxas de síntese e morte de tecidos por perfilho aliadas à estimativas do número de perfilhos por área (Davies, 1993).

A síntese de tecidos, no caso de pastagens, pode ser determinada apenas para as folhas ou para a planta inteira (Davies, 1993). No caso de plantas tropicais cespitosas, as hastes podem representar uma porção significativa do material produzido, como pode ser observado pelos resultado obtidos por Andrade (1987), onde a relação folha:haste variou de 1,55 a 0,25 para o Colonião e de 1,75 a 0,40 para o Tobiatã. Neste caso, a avaliação da sua contribuição para a síntese de tecidos passa a ser interessante, não só por poderem estar participando da dieta como também por poderem significar uma limitação ao consumo por parte dos animais (Flores et al., 1993).

O fluxo de tecido foliar em um pasto pode ser estimado através do filocrono e da longevidade das folhas e/ou das taxas de alongamento e senescência.

Filocrono foi definido por Wilhelm \& McMaster (1995) como o intervalo (em tempo horário, graus dias, etc) entre o mesmo estádio de crescimento em duas folhas sucessivas. A principal dificuldade para sua quantificação é determinar um estádio que possa ser identificado com precisão nas folhas. As alternativas mais aceitas são usar o momento do aparecimento da folha ou o índice de Haun ${ }^{1}$. Em alguns casos, o filocrono

\footnotetext{
${ }^{1}$ Índice de Haun é calculado pela fórmula: $\left(\mathrm{C}_{n} / \mathrm{C}_{\mathrm{n}-1}\right)+(\mathrm{n}-1)$, onde $\mathrm{C}_{\mathrm{n}}$ é o comprimento da folha mais nova, $\mathrm{C}_{\mathrm{n}-1}$ é o comprimento da folha anterior à mais nova e $\mathrm{n}$ é o número total de folhas (WILHELM \& McMASTER, 1995).
} 
tem sido determinado medindo-se o tempo que uma folha leva para crescer. Isso, no entanto, só é válido para espécies que apresentam apenas uma folha crescendo de cada vez (Wilhelm \& McMaster, 1995).

A senescência é o processo de deterioração que acompanha o envelhecimento e leva à morte de um órgão ou organismo. Ela é geneticamente programada para cada espécie e para os órgãos e tecidos de cada planta (Salisbury \& Ross, 1992). Nas folhas, a senescência é acompanhada por perdas de clorofila, RNA e proteínas, incluindo enzimas (Lalonde \& Dhindsa, 1990; Salisbury \& Ross, 1992). A perda destes compostos provoca uma mudança de cor no tecido foliar, o que levou Wilman \& Mares-Martins (1977) a considerar como senescente ou morto os tecidos que se tornassem amarelos ou marrons, respectivamente.

As taxas de alongamento e senescência podem ser avaliadas por folha ou por perfilho e correspondem ao aumento em comprimento verde e senescente, respectivamente (Thomas, 1980).

O aparecimento, crescimento e morte de folhas em uma planta dependem de fatores genéticos (espécie, variedade) e do meio (temperatura, umidade, fotoperíodo, intensidade luminosa, nutrição mineral, presença de patógenos, etc) (Anslow, 1966; Thomas \& Stoddart, 1980).

Calvière \& Duru (1995) avaliaram a mudança de estádio de desenvolvimento, as taxas de aparecimento e senescência e a longevidade das folhas em cinco espécies forrageiras (Plantago lanceolata, Sanguisorba minor, Ranunculus repens, Taraxacum officinalis, Dactylis glomerata) e concluíram que estas características devem ser levadas em consideração quando se for comparar o crescimento de espécies diferentes.

Hume (1991) comparou três cultivares de Bromus willdenowii e dois cultivares de azevém quanto à produção de folhas e perfilhos durante os estádios vegetativo e reprodutivo. Esse autor observou diferenças entre as espécies e os cultivares quanto ao perfilhamento, taxa de aparecimento e tamanho de folhas, número de folhas por perfilho e tamanho das bainhas e da área foliar por planta. Frank \& Bauer (1995) estudaram as diferenças entre cultivares de trigo (Triticum aestivum, Titicum durum) e cevada 
(Hordeum vulgare) e de algumas espécies forrageiras (Agropyrum desertorum, Elymus smithii, Elytrigia intermedia, Phalaris arundinacea) e, apesar de não terem conseguido determinar os fatores genéticos específicos que influenciam no filocrono, verificaram a existência de variações entre os cultivares de uma dada espécie e entre clones de cultivares heterogêneos, o que sugere a importância da expressão genética na avaliação desta característica. Para azevém, foi observada a existência de variabilidade entre populações naturais em estádio vegetativo no tamanho da folha, filocrono, taxa de alongamento e tempo de alongamento (Hazard et al., 1996). Em Panicum virgatum, Esbroeck et al. (1997) encontraram diferenças entre o filocrono de cinco cultivares, sendo que o período vegetativo era mais prolongado naqueles onde o aparecimento de folhas era mais lento.

Para Hazard et al. (1996), essa variabilidade poderia ser usada no melhoramento genético, a fim de se obterem genótipos melhor adaptados ao pastejo. Esse autor ressalta, no entanto, que uma seleção muito específica nessa direção poderia reduzir a polivalência dos cultivares, ou seja, cultivares adaptados para cortes frequentes poderiam não responder bem sob cortes infrequentes, e vice-versa.

As características morfogenéticas do perfilho parecem depender, também, do seu estádio de desenvolvimento. Vine (1983), trabalhando com azevém, observou que nos perfilhos reprodutivos as folhas apareciam mais rapidamente que nos vegetativos, quando a comparação era feita para uma mesma temperatura do solo. Uma maior taxa de aparecimento de folhas também foi encontrada para os perfilhos reprodutivos de Bromus willdenowii, em um trabalho desenvolvido por Hume (1991).

Já o efeito do estádio de desenvolvimento sobre a taxa de alongamento foliar é menos claro. Kemp et al. (1989) desenvolveram um trabalho com azevém, onde as plantas foram estabelecidas no campo e, toda semana, amostras eram tiradas e levadas para casa de vegetação onde permaneciam por 48 horas sob condições controladas $\left(15^{\circ}\right.$ C e 16 horas de luz). Neste período era avaliada a taxa de expansão potencial das folhas e depois as plantas eram dissecadas para determinar o seu estádio de desenvolvimento. A taxa de alongamento foliar começou a aumentar logo após a iniciação floral, atingiu um 
pico e depois voltou a cair, sendo que no momento do florescimento já apresentava valores semelhantes aos de plantas vegetativas. $\mathrm{O}$ autor explica que os mecanismos que determinam este padrão de comportamento não são conhecidos, mas podem estar ligados à regulação hormonal.

Em contrapartida, Stapleton \& Jones (1987) observaram que para as folhas de azevém apresentarem altas taxas de alongamento bastava a planta passar por um período de baixas temperaturas, enquanto para indução floral eram necessários baixas temperaturas e dias longos. Isso os levou a concluir que não há ligação entre taxa de alongamento e indução floral. Ainda segundo esses autores, os dois processos ocorrem ao mesmo tempo em ambientes naturais devido às variações sazonais de temperatura e fotoperíodo. Experimentos com azevém e trigo confirmam a hipótese de que o início do florescimento e o aumento da taxa de alongamento das folhas são controlados de forma independente, apesar de serem desencadeados pelas mesmas condições de fotoperíodo e temperatura (Davies et al., 1989; Rawson, 1991).

Vários trabalhos confirmam um efeito do fotoperíodo no crescimento das plantas. Muchow \& Carberry (1989) e Muchow \& Carberry (1990), por exemplo, propuseram o uso de equações matemáticas envolvendo fotoperíodo e temperatura para descrever a fenologia e o desenvolvimento e manutenção da área foliar em culturas de milho e sorgo.

O efeito do fotoperíodo no crescimento, no entanto, está sujeito a uma série de interações, o que dificulta bastante a generalização dos resultados. Por exemplo, em um experimento com trevo, Arnott \& Ryle (1982) observaram que o aumento da temperatura e/ou do fotoperíodo acelerava a taxa de aparecimento e expansão de folhas e aumentava o comprimento dos pecíolo e a área final da folha. Já em Vigna unguiculata a taxa de aparecimento foliar dependeu apenas da temperatura, não sofrendo influência do fotoperíodo (Craufurd et al., 1997). Esses resultados contraditórios sugerem que cada espécie responde de uma forma diferente ao fotoperíodo.

Outro fator que deve ser considerado na interpretação de experimentos com fotoperíodo é se houve mudança na quantidade total de energia recebida pela planta 
(Anslow, 1966). Na realidade, o efeito da luminosidade sobre o crescimento e morte de tecidos vai depender do fotoperíodo, da intensidade luminosa e da qualidade da luz que atinge as folhas.

O efeito da intensidade de luz sobre o crescimento de folhas de trigo foi estudado por Dale (1982). Ele observou que a área foliar foi pouco afetada por mudanças na temperatura e na intensidade de luz, apesar da taxa de alongamento ter sido maior quando a temperatura e intensidade de luz eram altas. Os autores concluíram que houve uma compensação entre taxa e tempo de alongamento. Nos tratamentos onde havia mais luz, o peso das folhas foi maior, o que foi atribuído ao maior peso das células visto que $o$ número não diferiu. Para Brachiaria brizantha e Panicum maximum var. trichoglume foi observado que altas intensidades de luz estimulavam o crescimento, perfilhamento, produção por perfilho e proporção de haste (Deinum et al., 1996).

Ferraris et al. (1986) trabalharam com capim elefante e observaram que existe uma interação entre os efeitos de temperatura e intensidade de luz sobre o crescimento. Neste experimento, a temperatura ótima para crescimento foi entre $33 / 28{ }^{\circ} \mathrm{C}$ (dia/noite), sendo que a quantidade de matéria seca produzida dependeu da radiação solar recebida e, exceto para as temperaturas mais baixas, a produção acumulada dependeu da radiação acumulada. Esse efeito da intensidade luminosa sobre o crescimento pode estar ligado à taxa liquida de fotossíntese (Woledge, 1972).

A intensidade de luz também interfere no tempo de vida das folhas. Em Lolium sp. a longevidade das folhas foi reduzida sob condições de sombreamento severo (Woledge, 1972) e para Arabidopsis thaliana foi observado que a senescência das folhas era controlada pela quantidade de luz e não pelo fotoperíodo (Noodën et al., 1996).

À medida que uma planta cresce, o auto-sombreamento faz com que as folhas em desenvolvimento recebam menores quantidades de luz azul e que a relação entre luz vermelha e ultra vermelha fique mais estreita. Essas mudanças na qualidade da luz são revertidas após um corte ou pastejo. Esse fato levou Gautier \& Varlet-Grancher (1996) a estudarem o efeito do nível de luz azul sobre diversas características morfogenéticas em festuca (Festuca arundinacea) e azevém perene. A redução da luz azul provocou um 
aumento no comprimento das lâminas e das bainhas foliares nas duas espécies, sendo que o aumento da luz revertia o processo. Esse fato foi atribuído a uma maior taxa de alongamento das folhas. No caso da festuca, a redução de luz azul aumentou também o tempo de alongamento e o intervalo entre aparecimento de folhas, o que ajuda a explicar o maior comprimento foliar e sugere que o desenvolvimento de folhas sucessivas nesta espécie é correlacionado.

Dentre os fatores climáticos que interferem no crescimento das plantas, a temperatura parece ser um dos mais importantes. Uma prova disso são as diversas tentativas de se construírem modelos matemáticos para simular o aumento e manutenção da área foliar através de graus dias (Hesketh \& Warrington, 1989; Hodges \& Evans, 1992; Gillen \& Ewing, 1992).

Em azevém, mudanças na temperatura foram responsáveis por $60,4 \%$ na variação da taxa da alongamento foliar, sendo que o restante deve ter sido decorrente de diferenças em outros fatores do meio (radiação, etc) (Baker \& Younger, 1987). Gastal et al. (1992) observaram que em festuca a taxa de alongamento era bastante influenciada pela temperatura e que quando não havia limitação de nitrogênio a correlação era maior. Nesse experimento, o efeito da temperatura no crescimento foliar dependeu também do estádio de desenvolvimento do perfilho. King et al. (1995) compararam três espécies de festuca e observaram que, apesar da temperatura ter exercido influência no padrão de crescimento das três, a resposta de cada uma foi diferente.

Collins \& Jones (1988) observaram que em Cyperus longus, uma planta de ciclo $\mathrm{C}_{4}$, o aumento da temperatura provocou mudanças no padrão de crescimento das folhas, aumentando a taxa de aparecimento e de alongamento, porém reduzindo o tempo de crescimento, sendo que o tamanho final das folhas foi função da sua posição na planta. Segundo Hay \& Walker (1989), taxas elevadas de expansão foliar e altas temperaturas geralmente encurtam o tempo de alongamento foliar, porém existe pouca evidência experimental de uma compensação entre tempo e taxa de alongamento de modo a resultar no mesmo tamanho final da folha em temperaturas diferentes. 
Alguns modelos matemáticos procuram descrever o efeito da temperatura no desenvolvimento foliar correlacionando o parâmentro estudado com graus dias, o que exige a determinação da temperatura basal. Na maior parte dos casos, atribui-se um valor arbitrário para a temperatura basal, no entanto, Unruh et al. (1996) verificaram que estã é característica de cada espécie e cultivar e que o uso de valores médios pode levar a uma imprecisão muito grande nos cálculos de graus dias.

A disponibilidade de água para a planta também interfere no crescimento. Em Hyparrhenia filipendula, Coughenour et al. (1985) verificaram que quando se reduzia a frequência de irrigação a taxa de alongamento ficava menor. Ainda neste experimento, o número de perfilhos dependeu do nível de nitrogênio aplicado, sendo que a produção foi máxima quando havia disponibilidade de nitrogênio e água. Para Panicum maximum cv. Tobiatã, Dias Filho et al.(1989) observaram que o estresse hídrico reduzia a taxa de alongamento e o número de folhas por perfilho Os resultados deste experimento sugerem que quando a planta se desenvolve em situação de deficiência hídrica ela suporta melhor periodos de restrição de água que plantas que cresceram desde o início sob condições adequadas de umidade. Thomas (1991) observou no azevém que após oito semanas de seca o alongamento foliar havia parado, as pontas das lâminas estavam queimadas, as membranas celulares danificadas e o potencial osmótico havia caído.

A resposta da planta ao estresse vai depender do nível de restrição a que ela é submetida. Em pastos consorciados de azevém perene e trevo branco, foi demonstrado que déficits de água de 50 ou $60 \mathrm{~mm}$ limitavam a taxa de alongamento foliar, e que quando este passava para $140 \mathrm{~mm}$ as folhas praticamente paravam de crescer. Os autores verificaram, no entanto, que após uma chuva o nível de crescimento aumentava rapidamente (Parfitt et al., 1985 a; Parfitt et al., 1985 b). Segundo Milthorpe \& Moorby (1974), a divisão celular é menos afetada pelo déficit hídrico do que a expansão, o que resulta em um tipo de crescimento compensatório da folha quando essa condição é interrompida.

Em um trabalho conduzido no Canadá com três espécies forrageiras (Bromus inermis, Agropyron cristatum e Leymus angustatus) a senescência sofreu influência da 
disponibilidade de água. Neste experimento, o potencial de água abaixo do qual ocorria a senescência induzida dependeu da espécie, sendo que nos perfilhos vegetativos o efeito era menor que nos reprodutivos (Bittman, 1985). Para milho foi observado que o estresse hídrico e a falta de nitrogênio aumentavam a senescência (Wolfe, 1988 a, b). Já em um experimento com azevém, conduzido por Barker et al. (1989), as taxas de aparecimento e alongamento das folhas foram sensíveis ao estresse hídrico, enquanto a senescência e morte não.

A necessidade de nutrir adequadamente uma planta para que ela cresça e se desenvolva é conhecida e aceita há muito tempo, porém muitos mecanismos deste processo ainda precisam ser elucidados. Ingestad (1981) encontrou fortes regressões lineares entre qualquer combinação de duas das seguintes variáveis: taxa relativa de adição de nutrientes, taxa de crescimento relativo e teor de nutrientes nas plantas.

Os elementos $\mathrm{K}, \mathrm{Cl}, \mathrm{Ca}, \mathrm{Mg}$, e $\mathrm{P}$ mostraram diferentes padrões de distribuição avaliados em termos de densidade iônica em folhas de milho. $\mathrm{O} \mathrm{K} \mathrm{e} \mathrm{o} \mathrm{Cl}$ apresentaram densidades mínimas nas pontas das folhas; a densidade de $\mathrm{K}$ foi máxima na região de crescimento, enquanto a de $\mathrm{Cl}$ foi mais alta na região de final de crescimento. $\mathrm{O} \mathrm{Ca}, \mathrm{Mg}$ e P apresentaram densidades relativamente maiores na base da zona de alongamento e nas extremidades. Na base da zona de alongamento, o $\mathrm{P}$ e o $\mathrm{Mg}$ apresentaram maiores densidades nas folhas novas em crescimento, enquanto nas folhas velhas completamente expandidas o $\mathrm{Ca}$ apresentou maior densidade. A taxa de deposição de todos nutrientes foi maior na região de máximo alongamento ( Meiri et al., 1992 ).

A presença daqueles nutrientes na zona de alongamento foliar é explicada pelo papel que os mesmos desempenham. O K é bastante importante para o crescimento, sendo que sua principal função na taxa de expansão foliar parece estar relacionada à ativação da ATPase na membrana plasmática ( Haschke \& Luttage, citados por Meiri et al., 1992). As maiores concentrações de $P$ na zona de crescimento refletem os altos conteúdos de ácido nucléico nas células em divisão. Altas concentrações de $\mathrm{Mg}$ nas células em divisão permitem altas taxas de síntese protéica e polimerização do RNA (Marschner, citado por Meiri et al., 1992). 
Apesar dos diversos nutrientes participarem do processo de crescimento da planta, o $\mathrm{N}$ parece ter um papel de destaque, como pode ser visto pelas seguintes conclusões:

“Os teores de K, P, Ca e Mg nas plântulas tiveram uma influência secundária no crescimento quando os niveis de $\mathrm{N}$ estavam abaixo do ótimo, visto que as correlações entre o teor de $\mathrm{N}$ e a taxa de crescimento foram extremamente altas" (Ingestad, 1979).

'Dentro de certos limites, os dados obtidos suportam que a taxa de crescimento da planta é aproximadamente proporcional à sua porcentagem de $\mathrm{N}$, quando essa é menor que a concentração crítica" (Greenwood et al., 1986).

$\mathrm{O}$ crescimento da lâmina foliar é diferente para mono e dicotiledôneas. No caso de gramíneas, que são monocotiledôneas, a lâmina é gerada a partir de filas de células formadas em uma zona meristemática, que se desenvolve na base do primórdio foliar. Quando uma folha emerge na base das folhas mais velhas que a circundam, a porção visível está totalmente expandida e atinge rapidamente a máxima capacidade fotossintética. Desta forma, uma folha em crescimento mostra todos os estádios de desenvolvimento, do mais imaturo no meristema ao totalmente diferenciado e funcional na ponta (Dale, 1992).

$\mathrm{O}$ tamanho final de uma folha é determinado pelo número de células primordiais, taxa de divisão celular, duração da fase de divisão celular e tamanho das células maduras, e isso varia a depender da planta e de sua nutrição (Humphries \& Wheeler, 1963).

Volenec \& Nelson (1983) testaram o efeito de dois níveis de $\mathrm{N}$ na taxa de alongamento foliar em festuca e encontraram que esta foi $89 \%$ maior com alta dose de $\mathrm{N}$. Neste caso, o tamanho final das células da epiderme não sofreu influência do $\mathrm{N}$, porém o número de células epidermiais produzidas por fila por dia aumentou $90 \%$ com altos níveis de N, sugerindo um maior efeito deste na divisão celular. Em outro trabalho com festuca, se observou que alta fertilização nitrogenada aumentou a porcentagem de células do mesófilo em divisão. A relação entre células do mesófilo e da epiderme 
também aumentou, indicando um maior efeito do $\mathrm{N}$ na divisão celular do mesófilo (MacAdam et al., 1989).

O início da senescência pode ser influenciado pela nutrição mineral da planta. Clorose, necrose e senescência da folha são sintomas típicos de deficiência mineral. É muito comum um processo de senescência ser iniciado como resposta direta à deficiência, resultando na redistribuição do nutriente limitante dos tecidos velhos para estruturas em desenvolvimento como folhas novas e frutos. Isso é particularmente observado para nutrientes móveis como $\mathrm{N}, \mathrm{K}, \mathrm{P}, \mathrm{Mg}, \mathrm{Na}, \mathrm{Cl}$ (Thomas \& Stoddart, 1980).

De forma semelhante ao que foi verificado para a expansão foliar, o $\mathrm{N}$ é considerado o principal nutriente relacionado à senescência. Wolfe et al. (1988 a, b) trabalhando com milho verificaram que a deficiência de $\mathrm{N}$ reduziu a longevidade das folhas.

O conteúdo de Rubisco dependeu do teor de $\mathrm{N}$ nas folhas de Phaseolus vulgaris e Alocasia macrorrhiza. (Seemam et al., 1987). A Rubisco é a enzima responsável pela reação onde o $\mathrm{CO}_{2}$ atmosférico é fixado nas plantas, logo a sua redução significa uma diminuição na fotossintese foliar. Wolfe et al. (1988 a, b) observaram, que em milho, a deficiência de nitrogênio reduziu a longevidade, a capacidade fotossintética e os níveis de clorofila e nitrogênio nas folhas.

A produção líquida de uma pastagem depende do balanço entre a taxa de crescimento e senescência dos tecidos. Wilman \& Mohamed (1980) trabalhando com Lolium perenne e Festuca arudinacea mostraram que a aplicação de $\mathrm{N}$ aumenta a taxa de alongamento e também a proporção de folhas verdes. Em uma área consorciada de azevém e trevo, Laidlaw \& Steen (1989) verificaram que o aumento da adubação nitrogenada levou a uma maior taxa de expansão e menor taxa de senescência. Esses efeitos aliados a uma maior densidade populacional de perfilhos determinaram que, nas áreas que receberam mais nitrogênio, tanto a produção bruta quanto a líquida fossem maiores. Segundo Wilman \& Mares-Martins (1977) e Pearse \& Wilman (1984), o efeito do $\mathrm{N}$ na porcentagem de tecido verde com relação à produção total de forragem é mais 
acentuado no início da rebrota, pois este nutriente reduz a taxa de senescência nas primeiras semanas, porém acelera a mesma depois.

O manejo interfere nas taxas de crescimento e morte em um pasto e, apesar destes valores serem diferentes para um pasto que está aumentando, diminuindo ou sendo mantido sob determinado índice de área foliar, Parsons et al. (1988) consideraram que o padrão de comportamento da planta quando comparado em mesmos valores de IAF é semelhante nas áreas sob pastejo contínuo e rotacionado. Diversos estudos mostram que a taxa de crescimento aumenta com o IAF. A senescência também aumenta, sendo que no inicio ela é menor que a produção e depois passa a compensar a mesma, de tal forma que não ocorrem mais acúmulos líquidos. Em valores de IAF muito altos, a senescência se torna maior que a produção, e a taxa de acúmulo líquido passa a ser decrescente (Bircham \& Hodgson, 1983; Grant et al. ,1983; King et al., 1984; Parsons \& Penning, 1988).

Em pastagens de gramíneas, existe uma compensação entre peso e número de perfilhos, sendo que a produção se mantém relativamente estável sob diferentes condições de manejo (Matthew et al., 1995). Quando esse equilíbrio é quebrado, a produção do pasto cai rapidamente, mostrando a necessidade de correções no manejo. No experimento conduzido por Grant et al. (1983) em áreas ocupadas predominantemente por azevém, alturas de pastejo menores que $2 \mathrm{~cm}$ determinaram um aumento na morte de perfilhos e uma progressiva substituição do azevém por outras espécies.

O efeito do manejo sobre a densidade populacional de perfilhos foi bem estudado em pastagens temperadas. Jones et al. (1982) observaram que o número de perfilhos por área era maior sob pastejo contínuo que rotacionado em área exclusivas de azevém e Champman et al. (1983) encontraram o mesmo resultado trabalhando com pastagens de azevém consorciado. No pastejo contínuo, a densidade populacional de perfilhos tende a ser relativamente alta e constante ao longo do ano, enquanto em pastejo rotacionado o número de perfilhos atinge um pico na primavera e depois cai rapidamente durante a fase reprodutiva, mantendo-se mais ou menos estável no resto do ano (Hodgson, 1990). 
Em áreas sob pastejo rotacionado, o intervalo entre desfolhas é um dos fatores que pode interferir no perfilhamento. Em um experimento conduzido por Costa et al. (1992), a densidade populacional de perfilhos em colonião e tobiatã não diferiu quando os cortes eram efetuados a cada 28 e 35 dias, porém o aumento do intervalo entre desfolhas para 42 dias determinou uma redução no número de perfilhos por área.

A severidade de pastejo também interfere no perfilhamento. Para azevém sob pastejo contínuo, foi observado que o maior número de perfilhos por área era obtido quando o pasto era mantido com 2 a $3 \mathrm{~cm}$. Acima desta altura, a densidade populacional era limitada pela competição entre os indivíduos e abaixo dela a mortalidade de perfilhos aumentava muito (Bircham \& Hodgson, 1983; Grant et al., 1983). Tallowin et al. (1989) determinaram que em áreas de azevém mantidas a $7,5 \mathrm{~cm}$ através de pastejo contínuo a produção de perfilhos era menor que em áreas a $3,5 \mathrm{~cm}$, sendo este fato o principal responsável pela menor densidade populacional de perfilhos. Esses autores observaram também que a produção de perfilhos no pastejo mais suave parecia ser limitada pela inibição do desenvolvimento das gemas, uma vez que a taxa de aparecimento de folhas, e consequentemente de formação de gemas, não diferiu entre os tratamentos.

Fisher \& Dowdeswell (1995) conduziram um experimento com azevém para avaliar o efeito da rebrota e da manutenção de determinada altura do pasto sobre o perfilhamento. A área foi pastejada por carneiros a uma altura de $3 \mathrm{~cm}$ para se obter elevadas densidades populacionais de perfilhos. Após aproximadamente um mês, os animais foram retirados e quatro níveis de rebrota foram aplicados: até $6,9,12$ ou $15 \mathrm{~cm}$ de altura. Depois, as parcelas passaram a ser cortadas duas vezes por semana para manter uma altura de 6 ou $9 \mathrm{~cm}$. Os autores observaram que quando a rebrota atingia mais de $8,9 \mathrm{~cm}$ a densidade populacional de perfilhos caia e que as áreas mantidas a 6 $\mathrm{cm}$ apresentavam maior número de perfilhos do que aquelas mantidas a $9 \mathrm{~cm}$.

O efeito do nível de desfolha sobre o estímulo das gemas axilares pode ser decorrente da eliminação de dominância apical (Richards et al., 1988) ou de mudanças no microclima da região das gemas através, por exemplo, de alterações na qualidade e quantidade de luz (Auda et al., 1966; Casal et al., 1990) 
O perfilhamento depende também de outros fatores como temperatura, nutrição mineral e espécie ou cultivar (Auda, 1966; George \& Reigh, 1987; Mazzanti et al., 1994). Ferraris et al. (1986) observaram que houve uma interação entre os efeitos de temperatura e radiação solar no perfilhamento de capim elefante, sendo que a temperatura ótima para a produção de perfilhos dependeu do nível de radiação recebido. Em Panicum maximum var. trichoglume e Bachiaria brizantha o perfilhamento foi estimulado pelo aumento da intensidade de luz em um experimento conduzido em casa de vegetação com temperatura controlada (Deinum et al., 1996). King et al. (1995), comparando três espécies de festuca, observaram que o número de perfilhos por planta era maior com temperaturas de $17 / 13{ }^{\circ} \mathrm{C}$ (dia/noite) e que em apenas dois dos cinco cortes realizados houve interação entre os efeitos de espécie e temperatura. Coughenour et al. (1985) observaram que o número de perfilhos dependeu do nível de nitrogênio aplicado e que houve uma compensação entre peso e número de perfilhos.

Como pôde-se observar ao longo desta revisão, existe um forte componente genético que interfere na dinâmica de tecidos em pastagens. A maior parte dos experimentos básicos, que estudam o efeito isolado de fatores como temperatura, luminosidade e nutrição mineral nas taxas de crescimento, senescência e perfilhamento, foram feitos com plantas temperadas. Desta forma, apesar de se considerar que os princípios gerais sejam os mesmos, não se pode extrapolar os resultados obtidos nestes trabalhos para plantas tropicais. 


\section{3) MATERIAL E MÉTODOS}

O experimento foi conduzido no Departamento de Zootecnia da ESALQ/USP, em Piracicaba-SP $\left(22^{\circ} 42^{\prime} 30^{\prime \prime} \mathrm{S}\right.$ e $\left.47^{\circ} 38^{\prime} 30^{\prime \prime} \mathrm{W}\right)$, no período de outubro de 1995 a outubro de 1996. O solo do local é classificado como terra roxa estruturada com as seguintes características químicas: $\mathrm{pH}$ em $\mathrm{CaCl}_{2}=5,8$; matéria orgânica $=27 \mathrm{~g} / \mathrm{dm}^{3} ; \mathrm{P}$ (resina) $=$ $73 \mathrm{mg} / \mathrm{dm}^{3} ; \mathrm{S}=36,6 \mathrm{mg} / \mathrm{dm}^{3} ; \mathrm{K}=11,8 \mathrm{mmolc} / \mathrm{dm}^{3} ; \mathrm{Ca}=73,5 \mathrm{mmolc} / \mathrm{dm}^{3} ; \mathrm{Mg}=29,8$ $\mathrm{mmolc} / \mathrm{dm}^{3} ; \mathrm{H}+\mathrm{Al}=19,5 \mathrm{mmolc} / \mathrm{dm}^{3} ; \mathrm{Al}=0 \mathrm{mmolc} / \mathrm{dm}^{3} ; \mathrm{CTC}=134,5 \mathrm{mmolc} / \mathrm{dm}^{3} ; \mathrm{V}$ $=85,5 \%$. Os capins foram plantados em dezembro de 1994. O delineamento experimental foi de blocos completos ao acaso com parcelas subdivididas no tempo. Havia sete repetições para cada tratamento. Cada parcela tinha aproximadamente 130 $\mathrm{m}^{2}$. Os dados de precipitação e temperatura durante o período experimental podem ser vistos na Figura 1.

Foi feito um corte de igualação em outubro de 1995. A partir daí as parcelas eram pastejadas a cada 28,38 ou 48 dias, conforme o tratamento. Durante o verão, o tempo de pastejo para cada tratamento era de dois dias, e no inverno de um dia. O resíduo pós pastejo foi em média 2.300 e $1.900 \mathrm{~kg} /$ ha para os capins Mombaça e Tanzânia, respectivamente. As adubações eram feitas sempre após a saída dos animais. Todos os tratamentos receberam $400 \mathrm{~kg} / \mathrm{ha}$ de nitrogênio na forma de uréia durante o verão, divididos em 6,5 e 4 aplicações para 28,38 e 48 dias de intervalo entre pastejos, respectivamente. 


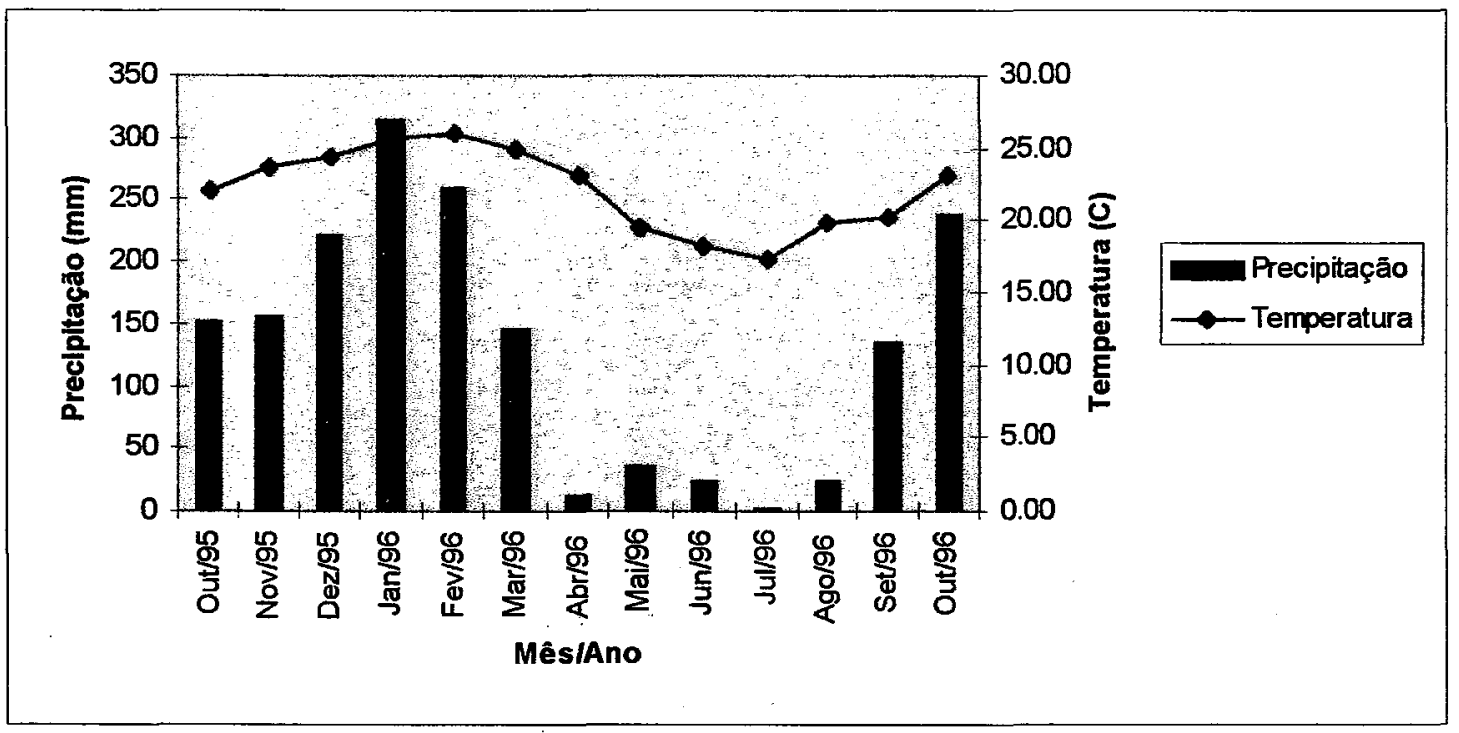

Figura 1: Precipitação $(\mathrm{mm})$ e temperatura média mensal $\left({ }^{\circ} \mathrm{C}\right)$ de outubro de 1995 a outubro de 1996.

A dinâmica de tecidos era avaliada em dez perfilhos por parcela, localizados ao longo de uma linha transversal. Os perfilhos eram marcados com fios de arame colorido, amarrados a um pedaço de plástico de $10 \mathrm{~cm}^{2}$, para facilitar a sua localização. Antes de cada pastejo eram feitas três medidas, com intervalos de dois (verão) ou três (inverno) dias, onde se anotava o comprimento das hastes (do solo até a última lígula) e o comprimento verde de cada lâmina foliar (da lígula até a ponta ou fim da parte verde, nas folhas expandidas e da lígula da folha anterior até a ponta, nas folhas em expansão). Com isso foi possível calcular:

- Taxa de alongamento foliar (cm/dia.perfilho): diferença entre o comprimento final e inicial das folhas em expansão dividida pelo número de dias entre as medidas.

- Taxa de senescência foliar ( $\mathrm{cm} /$ dia.perfilho): diferença entre o comprimento senescente final $\mathrm{e}$ inicial dividida pelo número de dias entre as avaliações. $\mathrm{O}$ comprimento senescente correspondia à redução observada no comprimento verde das folha (media-se apenas o comprimento verde de cada folha). 
- Taxa de alongamento da haste ( $\mathrm{cm} /$ dia.perfilho): diferença entre comprimento final e inicial das hastes dividida pelo número de dias entre as medições.

- Número de folhas vivas por perfilho ${ }^{2}$ : diferença entre o número total e o número de folhas mortas. As folhas eram consideradas mortas quando $50 \%$ da área estava amarelecida.

- Comprimento de folhas verdes por perfilho $(\mathrm{cm})^{2}$ : somatório do comprimento verde de todas as folhas do perfilho.

- Comprimento das hastes $(\mathrm{cm})^{2}$ : comprimento do solo até a última lígula.

Além disso, foram determinados:

-Número de perfilhos por $\mathrm{m}^{2}$ : determinado um dia antes do pastejo. O valor de cada parcela era a média de quatro subamostras de $0,5 \mathrm{~m}^{2}(1,0 \times 0,5 \mathrm{~m})$.

- Altura: distância do solo ao topo do dossel, sem modificar a estrutura, ou seja, sem esticar ou comprimir as plantas. A altura era medida em quatro pontos aleatórios, dentro de cada parcela.

- Relação folha:haste: foi determinada apenas durante o verão. Era tirada uma amostra composta por parcela. O material era cortado ao nível do solo, levado para o laboratório, separado em haste (haste e bainha) e folha (lâmina foliar) e levado à estufa $\left(55^{\circ} \mathrm{C}\right)$ até peso constante.

No dia do pastejo, os 10 perfilhos avaliados para dinâmica de tecidos eram cortados e levados para o laboratório, onde se separava as hastes, as folhas expandidas e as folhas em expansão para determinar a relação entre peso e comprimento. Combinando-se estes dados com os de taxa de alongamento das folhas e hastes, taxa de senescência e densidade de perfilhos foram propostas algumas curvas de taxa de acúmulo para os capins Tanzânia e Mombaça durante $o$ ano.

\footnotetext{
${ }^{2} \mathrm{O}$ número de folhas vivas, o comprimento de folhas verdes e o comprimento das hastes corresponde à média das três medidas realizadas antes de cada pastejo.
} 
Para cada cultivar foi testado o efeito de três intervalos entre pastejos $(28,38$ e 48 dias) e sete períodos (14/11/1995 a 31/12/1995, 1/1/1996 a 17/2/1996, 18/2/1996 a 5/4/1996, 6/4/1996 a 23/5/1996, 24/5/1996 a 10/7/1996, 11/7/1996 a 27/8/1996 e 28/8/1996 a 14/9/1996).

O modelo matemático adotado foi:

$\mathrm{Y}_{\mathrm{ijk}}=\mu+\gamma_{\mathrm{i}}+\beta \mathrm{j}+\varepsilon_{\mathrm{ij}}+\pi_{\mathrm{k}}+\gamma \pi_{\mathrm{ik}}+\varepsilon_{\mathrm{ijk}}$, onde:

$Y_{\mathrm{ijk}}=$ observação do intervalo entre pastejos $\mathrm{i}$, no bloco $\mathrm{j}$, no período $\mathrm{k}$.

$\mu=$ média da população.

$\gamma_{\mathrm{i}}=$ efeito do intervalo entre pastejos $\mathrm{i}$.

$\beta \mathrm{j}=$ efeito do bloco $\mathrm{j}$.

$\varepsilon_{i j}=$ efeito da variação do acaso

$\pi_{\mathrm{k}}=$ efeito do período $\mathrm{k}$.

$\gamma \pi_{\mathrm{ik}}=$ efeito da interação entre o intervalo entre pastejos i e o período $\mathrm{k}$.

$\varepsilon_{i \mathrm{jk}}=$ efeito da variação do acaso

Algumas variáveis não apresentaram distribuição normal ou homogeneidade de variância e precisaram ser transformadas para ajustar o modelo. Os dados foram submetidos à análise de variância através do procedimento GLM do SAS. Para a comparação das médias foi utilizada a opção LSmeans (SAS, 1986). 


\section{4) RESULTADOS E DISCUSSÃo}

Os efeitos do intervalo entre pastejo e do período do ano sobre a taxa de alongamento foliar e das hastes, nos capins Mombaça e Tanzânia, podem ser vistos nas Tabelas 2 e 3, respectivamente.

Tabela 2: Efeito do intervalo entre pastejos e do período de avaliação sobre a taxa de alongamento foliar (cm/dia.perfilho) e das hastes (cm/dia.perfilho) no capim Mombaça.

\begin{tabular}{cccccccc}
\hline $\begin{array}{c}\text { Intervalo } \\
\text { entre }\end{array}$ & \multicolumn{7}{c}{ Período } \\
\cline { 2 - 7 } pastejos & $14 / 11-$ & $1 / 1-$ & $18 / 2-$ & $6 / 4-$ & $24 / 5-$ & $11 / 7-$ & $28 / 8-$ \\
& $31 / 12 / 95$ & $17 / 2 / 96$ & $5 / 4 / 96$ & $23 / 5 / 96$ & $10 / 7 / 96$ & $27 / 8 / 96$ & $14 / 9 / 96$ \\
\hline \multicolumn{7}{c}{ Taxa de alongamento foliar (cm/dia.perfilho) } \\
28 dias & $6,58^{\mathrm{Ab}}$ & $9,51^{\mathrm{Aa}}$ & $8,41^{\mathrm{Aa}}$ & $3,79^{\mathrm{Ac}}$ & $1,82^{\mathrm{Be}}$ & $1,03^{\mathrm{AB}}$ & $2,88^{\mathrm{Bd}}$ \\
38 dias & $7,00^{\mathrm{Ab}}$ & $7,48^{\mathrm{Bab}}$ & $8,20^{\mathrm{Aa}}$ & $3,24^{\mathrm{Ad}}$ & $1,95^{\mathrm{Be}}$ & $0,93^{\mathrm{B}}$ & $4,43^{\mathrm{Ac}}$ \\
48 dias & $7,61^{\mathrm{Aa}}$ & $8,26^{\mathrm{ABa}}$ & $7,69^{\mathrm{Aa}}$ & - & $2,38^{\mathrm{Ac}}$ & $1,17^{\mathrm{Ad}}$ & $4,46^{\mathrm{Ab}}$ \\
& \multicolumn{5}{c}{ Taxa de alongamento das hastes (cm/dia.perfilho) } \\
28 dias & $0,71^{\mathrm{Aa}}$ & $0,52^{\mathrm{Aa}}$ & $0,43^{\mathrm{Aa}}$ & $0,63^{\mathrm{Aa}}$ & $0,09^{\mathrm{Ab}}$ & $0,10^{\mathrm{Ab}}$ & $0,12^{\mathrm{Bb}}$ \\
38 dias & $0,55^{\mathrm{Aa}}$ & $0,31^{\mathrm{Aa}}$ & $0,47^{\mathrm{Aa}}$ & $0,50^{\mathrm{ABa}}$ & $0,08^{\mathrm{Ab}}$ & $0,11^{\mathrm{Ab}}$ & $0,43^{\mathrm{Aa}}$ \\
48 dias & $0,45^{\mathrm{Aa}}$ & $0,41^{\mathrm{Aa}}$ & $0,43^{\mathrm{Aa}}$ & $0,30^{\mathrm{Ba}}$ & $0,08^{\mathrm{Ab}}$ & $0,04^{\mathrm{Bc}}$ & $0,46^{\mathrm{Aa}}$ \\
\hline
\end{tabular}

${ }^{\mathrm{T}}$ Médias seguidas pela mesma letra na maiúscula coluna e minúscula na linha, não diferem significativamente $(\mathrm{p}<0,05)$.

${ }^{2}$ Dados analisados segundo a transformação logarítmica natural. As médias foram re-transformadas.

${ }^{3}$ Dados analisados segundo a transformação logarítmica decimal. As médias foram re-transformadas. 
Tabela 3: Efeito do intervalo entre pastejos e do período de avaliação sobre a taxa de alongamento foliar ( $\mathrm{cm} /$ dia.perfilho) e das hastes ( $\mathrm{cm} /$ dia.perfilho) no capim Tanzânia.

\begin{tabular}{cccccccc}
\hline $\begin{array}{c}\text { Intervalo } \\
\text { entre }\end{array}$ & $14 / 11-$ & $1 / 1-$ & $18 / 2-$ & $6 / 4-$ & $24 / 5-$ & $11 / 7-$ & $28 / 8-$ \\
pastejos & $31 / 12 / 95$ & $17 / 2 / 96$ & $5 / 4 / 96$ & $23 / 5 / 96$ & $10 / 7 / 96$ & $27 / 8 / 96$ & $14 / 9 / 96$ \\
\hline \multicolumn{7}{c}{ Taxa de alongamento foliar (cm/dia.perfilho) } \\
\cline { 2 - 7 } 28 dias & $5,83^{\mathrm{B} \mathrm{b}}$ & $7,27^{\mathrm{Aa}}$ & $7,75^{\mathrm{Aa}}$ & $3,86^{\mathrm{Ac}}$ & $1,96^{\mathrm{Bd}}$ & $1,24^{\mathrm{AB}}$ & $2,29^{\mathrm{Cd}}$ \\
38 dias & $6,53^{\mathrm{B} \mathrm{b}}$ & $7,45^{\mathrm{Aa}}$ & $7,47^{\mathrm{ABa}}$ & $3,21^{\mathrm{Bd}}$ & $2,05^{\mathrm{Be}}$ & $1,06^{\mathrm{Bf}}$ & $3,05^{\mathrm{Bc}}$ \\
48 dias & $9,94^{\mathrm{Aa}}$ & $7,42^{\mathrm{Ab}}$ & $6,70^{\mathrm{B} \mathrm{b}}$ & - & $2,66^{\mathrm{Ad}}$ & $1,46^{\mathrm{Be}}$ & $3,76^{\mathrm{Ac}}$ \\
& \multicolumn{5}{c}{ Taxa de alongamento das hastes (cm/dia.perfilho) } & \\
28 dias & $0,46^{\mathrm{B} \mathrm{d}}$ & $0,70^{\mathrm{Bc}}$ & $1,04^{\mathrm{Ab}}$ & $1,58^{\mathrm{Aa}}$ & $0,10^{\mathrm{Be}}$ & $0,10^{\mathrm{Ae}}$ & $0,14^{\mathrm{Be}}$ \\
38 dias & $0,61^{\mathrm{B} \mathrm{b}}$ & $0,85^{\mathrm{Bb}}$ & $0,87^{\mathrm{Ab}}$ & $2,16^{\mathrm{Aa}}$ & $0,08^{\mathrm{Bd}}$ & $0,10^{\mathrm{Ad}}$ & $0,29^{\mathrm{Ac}}$ \\
48 dias & $1,02^{\mathrm{B} \mathrm{b}}$ & $1,81^{\mathrm{Aa}}$ & $1,21^{\mathrm{Ab}}$ & $1,92^{\mathrm{Aa}}$ & $0,19^{\mathrm{Ad}}$ & $0,08^{\mathrm{Ae}}$ & $0,35^{\mathrm{Ac}}$ \\
\hline
\end{tabular}

${ }^{1}$ Médias seguidas pela mesma letra maiúscula na coluna e minúscula na linha, não diferem significativamente $(p<0,05)$.

${ }^{2}$ Dados analisados segundo a transformação raiz quadrada. As médias foram re-transformadas.

${ }^{3}$ Dados analisados segundo a transformação logarítmica natural. As médias foram re-transformadas.

Nos dois cultivares praticamente todos os perfilhos com 48 dias já haviam florescido e, consequentemente, parado de produzir folhas em abril/maio. Nestes casos, a taxa de alongamento foliar foi nula e esses dados foram desconsiderados na análise estatística para possibilitar o ajuste do modelo.

Não houve efeito do intervalo entre pastejos sobre a taxa de alongamento foliar do capim Mombaça em novembro/dezembro; fevereiro/abril e abril/maio. Em janeiro/fevereiro ela foi mais alta com 28 dias, mais baixa com 38 e intermediária com 48 dias de intervalo entre pastejos. Em maio/julho e agosto/setembro a taxa de alongamento foliar aumentou com o intervalo entre pastejos. Em julho/agosto ela foi menor com 38 do que com 48 dias de intervalo entre pastejos, não havendo diferença entre esses tratamentos e o de 28 dias. No capim Tanzânia, a taxa de alongamento não sofreu 
influência do intervalo entre pastejos no período de janeiro/fevereiro, diminuiu com o aumento do intervalo em fevereiro/abril e abril/maio e aumentou em novembro/dezembro, maio/julho e agosto/setembro. Em julho/agosto ela foi menor com 38 do que com 48 dias de intervalo entre pastejos, não havendo diferença entre esses tratamentos e o de 28 dias.

No capim Mombaça, não houve efeito do intervalo entre pastejos sobra a taxa de alongamento das hastes nos períodos de novembro/dezembro, janeiro/fevereiro, fevereiro/abril e maio/julho. Em abril/maio ela diminuiu com o aumento do intervalo entre pastejos. Em julho/agosto a taxa de alongamento das hastes foi menor com 48 dias que com 28 e 38 dias e em agosto/setembro ela foi menor com 28 dias que com 38 e 48 dias de intervalo entre pastejos. Já no capim Tanzânia, a taxa de alongamento das hastes foi maior com 48 que com 28 e 38 dias de intervalo entre pastejos em novembro/dezembro, janeiro/fevereiro e maio/julho, se manteve estável com o aumento do intervalo entre pastejos em fevereiro/abril, abril/maio e julho/agosto e foi menor com 28 que com 38 e 48 dias de intervalo entre pastejos em agosto/setembro

Nos dois cultivares é clara a estacionalidade das taxas de alongamento das folhas e das hastes, sendo que estas são maiores nos períodos de temperatura e precipitação mais elevadas (Figura 1). Isso se reflete na produção de forragem. Cecato et al. (1996) avaliando os dois cultivares entre janeiro e agosto determinaram que 81 e $73 \%$ da produção dos capins Mombaça e Tanzânia, respectivamente, se concentrou no período de maior precipitação e temperatura.

Para a taxa de senescência foliar, não houve interação entre pastejos e períodos, logo, apenas os efeitos principais foram analisados (Tabelas 4 e 5). 
Tabela 4: Efeito do intervalo entre pastejos sobre a taxa de senescência (cm/dia.perfilho) nos capins Mombaça e Tanzânia.

\begin{tabular}{|c|c|c|}
\hline \multirow{2}{*}{$\begin{array}{l}\text { Intervalo entre } \\
\text { pastejos (dias) }\end{array}$} & \multicolumn{2}{|c|}{ Taxa de senescência $(\mathrm{cm} / \text { dia.perfilho })^{1}$} \\
\hline & Capim Mombaça ${ }^{2}$ & Capim Tanzânia \\
\hline 28 & $0,74^{\mathrm{B}}$ & $0,34^{\mathrm{C}}$ \\
\hline 38 & $1,17^{\mathrm{B}}$ & $0,71^{\mathrm{B}}$ \\
\hline 48 & $2,07^{\mathrm{A}}$ & $2,01^{A}$ \\
\hline
\end{tabular}

Tabela 5: Efeito do período sobre a taxa de senescência ( $\mathrm{cm} /$ dia.perfilho) nos capins Mombaça e Tanzânia.

\begin{tabular}{ccc}
\hline Período & \multicolumn{2}{c}{ Taxa de senescência (cm/dia.perfilho) $^{\mathbf{1}}$} \\
\cline { 2 - 3 } & Capim Mombaça $^{2}$ & Capim $^{\text {Tanzânia }}{ }^{3}$ \\
\hline $14 / 11-31 / 12 / 95$ & $0,78^{\mathrm{B}}$ & $0,52^{\mathrm{B}}$ \\
$1 / 1-17 / 2 / 96$ & $1,74^{\mathrm{A}}$ & $1,13^{\mathrm{A}}$ \\
$18 / 2-5 / 4 / 96$ & $1,48^{\mathrm{A}}$ & $1,05^{\mathrm{A}}$ \\
$6 / 4-23 / 5 / 96$ & $1,19^{\mathrm{A}}$ & $0,64^{\mathrm{B}}$ \\
\hline
\end{tabular}

\footnotetext{
${ }^{1}$ Médias seguidas pela mesma letra na coluna não diferem significativamente $(\mathrm{p}<0,05)$.

${ }^{2}$ Dados analisados segundo a transformação logarítmica decimal. As médias foram re-transformadas.

${ }^{3}$ Dados analisados segundo a transformação raiz quadrada. As médias foram re-transformadas.
}

Tanto para o capim Tanzânia quanto para o capim Mombaça, houve um aumento da taxa de senescência com o intervalo entre pastejos, principalmente quando se passou de 38 para 48 dias.

Em um experimento conduzido por Barbosa et al. (1996), o aumento da senescência foi mais tardio. Esses autores não observaram aumento do número de folhas senescentes 
nos capins Tanzânia e Mombaça durante 35 dias de crescimento no verão e 49 no outono. Na primavera e no inverno, com períodos de crescimento de 70 e 63 dias, respectivamente, houve aumento da senescência apenas para o capim Mombaça.

A taxa de senescência a partir de maio foi insignificante e, por isso, os resultados foram desconsiderados na análise estatística. De modo geral, ela foi maior nos períodos de janeiro/fevereiro e fevereiro/abril, sendo que no capim Mombaça, a diferença entre estes períodos e o período abril/maio não chegou a ser significativa.

A menor taxa de senescência durante abril/maio pode ser decorrente da grande proporção de perfilhos reprodutivos (Hunt \& Brougham, citados por Davies, 1971). Durante a fase reprodutiva ocorre a alongamento da haste, melhorando a distribuição de luz e reduzindo o sombreamento sobre as folhas mais baixas. A mudança na luminosidade pode ter contribuído para a diminuição da taxa de senescência destas folhas (Woledge et al., 1972; Noodën, 1996). Além disso, com a diferenciação do meristema apical, ocorrem diversas alterações no balanço hormonal da planta, o que também pode interferir na senescência das folhas.

Para a densidade populacional de perfilhos, apenas o efeito do período foi significativo (Tabela 6).

Nos dois cultivares, a maior densidade populacional de perfilhos foi observada em novembro/dezembro e a menor em abril/maio. No restante do ano ela se manteve relativamente constante. Os baixos valores obtidos em abril/maio podem ser justificados pelo aumento do tamanho dos perfilhos e pela maior competição entre os mesmos em virtude do florescimento (Hodgson, 1990). 
Tabela 6: Efeito do período sobre a densidade populacional de perfilhos (perfilhos $/ \mathrm{m}^{2}$ ) nos capins Mombaça e Tanzânia.

\begin{tabular}{|c|c|c|}
\hline \multirow[t]{2}{*}{ Período } & \multicolumn{2}{|c|}{ Número de perfilhos (perfilhos $\left./ \mathrm{m}^{2}\right)^{1}$} \\
\hline & Capim Mombaça $^{2}$ & Capim Tanzânia ${ }^{3}$ \\
\hline $14 / 11-31 / 12 / 95$ & $245^{A}$ & $359^{\mathrm{A}}$ \\
\hline $1 / 1-17 / 2 / 96$ & $145^{\mathrm{BC}}$ & $208^{\mathrm{BC}}$ \\
\hline $18 / 2-5 / 4 / 96$ & $163^{\mathrm{B}}$ & $172^{\mathrm{C}}$ \\
\hline $6 / 4-23 / 5 / 96$ & $110^{\mathrm{D}}$ & $136^{\mathrm{D}}$ \\
\hline $24 / 5-10 / 7 / 96$ & $155^{\mathrm{BC}}$ & $200^{\mathrm{BC}}$ \\
\hline $11 / 7-27 / 8 / 96$ & $140^{\mathrm{BC}}$ & $234^{\mathrm{B}}$ \\
\hline 28/8-14/9/96 & $135^{\mathrm{C}}$ & $218^{B}$ \\
\hline
\end{tabular}

Apesar do delineamento experimental adotado não permitir a comparação dos dois cultivares, vale a pena chamar a atenção para o fato de que a taxa de senescência do capim Tanzânia correspondeu a aproximadamente $2 / 3$ do observado para o capim Mombaça, exceto para 48 dias de intervalo entre pastejos, quando a taxa de senescência dos dois capins foi semelhante (Tabelas 4 e 5). É interessante observar também que a densidade populacional de perfilhos do capim Tanzânia tendeu a ser maior que a do capim Mombaça em todos os períodos do ano. Isso indica a necessidade de se adotar estratégias de manejo diferentes para os dois cultivares.

As Figuras 2, 3 e 4 mostram as taxas de acúmulo líquido e de senescência nos capins Mombaça e Tanzânia nos períodos de outubro a abril, abril a maio e maio a setembro, respectivamente. Esse valores estão expressos como porcentagem da máxima taxa de acúmulo total. Como não houve efeito do intervalo entre cortes sobre o número de perfilhos, as taxas de acúmulo líquido de matéria seca e de senescência refletiram as variações das taxas de alongamento e senescência de folhas e hastes. 
a)

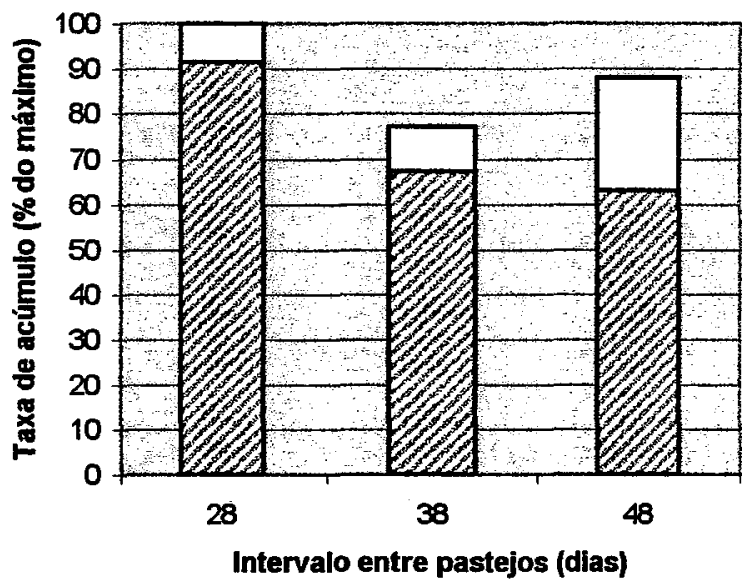

b)

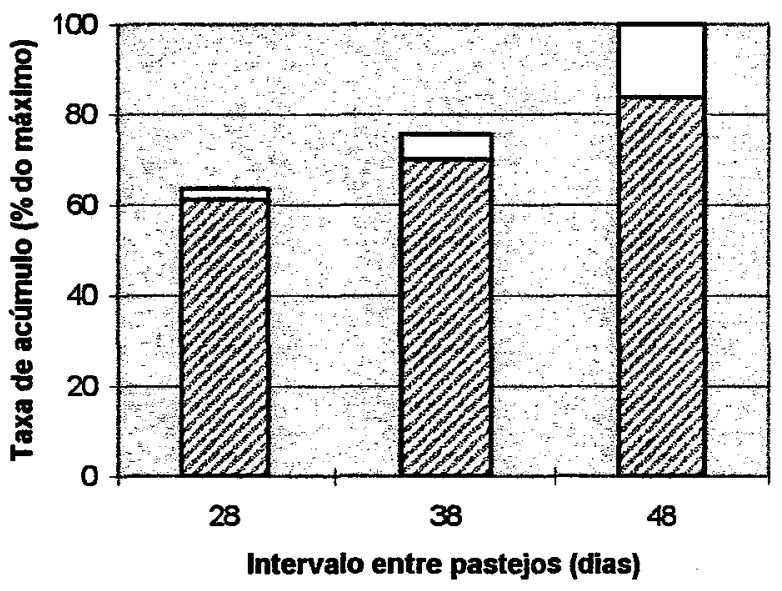

口Senescência ETaxa líquida

Figura 2: Taxa de acúmulo líquido e de senescência entre novembro de 1995 e abril de 1996 (estádio vegetativo) para a) capim Mombaça e b)capim Tanzânia. 
A taxa de acúmulo líquido do capim Mombaça (Figura 2.a) tendeu a decrescer de 28 para 48 dias de intervalo entre pastejos, sendo que essa redução foi mais expressiva entre 28 e 38 dias. Já no caso do capim Tanzânia (Figura 2.b), a taxa de acúmulo líquido tendeu a aumentar de forma praticamente constante com o intervalo entre pastejos. Nos dois cultivares, a taxa de senescência aumentou com o intervalo entre pastejos, principalmente quando se passou de 38 para 48 dias.

Esses dados sugerem que entre novembro e abril o capim Mombaça deve ser pastejado com 28 dias ou menos. A extensão do intervalo entre pastejos pode acarretar em redução da produção, já que a taxa de alongamento de folhas e hastes não difere entre os períodos de descanso (Tabela 2), mas a taxa de senescência aumenta (Tabela 4).

Para o capim Tanzânia, os resultados sugerem que com períodos de descanso até 48 dias não haverá redução na produção, porém a eficiência de pastejo será mais alta se o periodo de descanso for inferior a 38 dias. Isso ocorre porque as taxas de alongamento de folhas e/ou hastes são elevadas nos intervalos maiores de descanso (exceto em fevereiro/abril) (Tabela 3). Sugere-se a desfolha a cada 38 dias no período de novembro a abril em decorrência da maior taxa de senescência observada nas plantas pastejadas a cada 48 dias (Tabela 4) 
a)

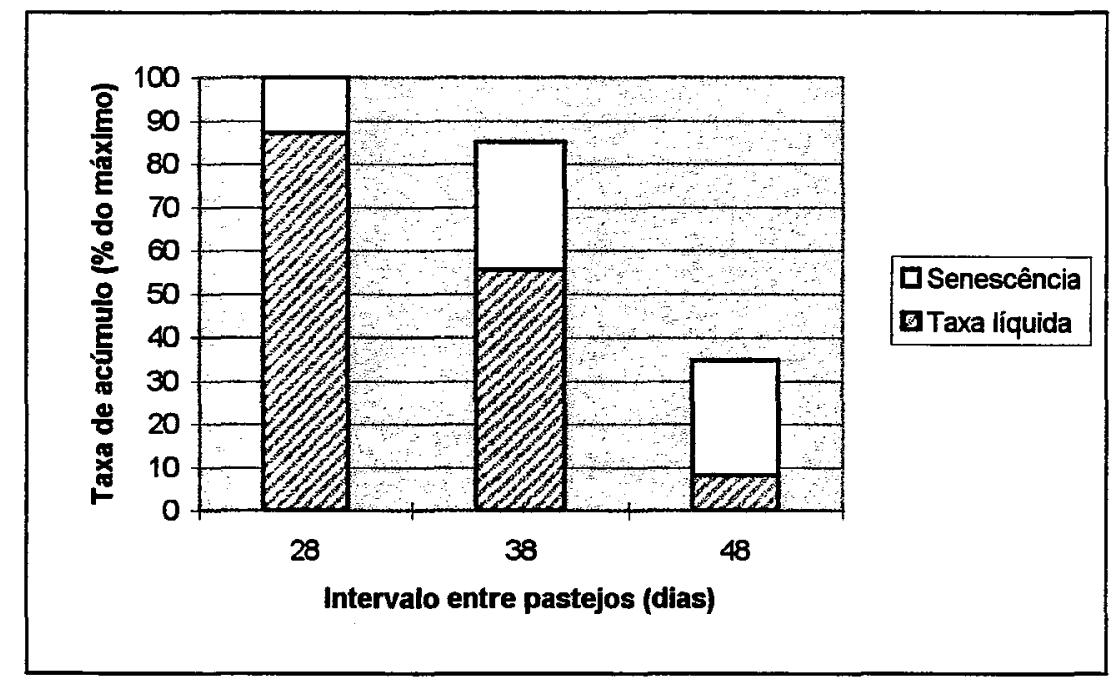

b)

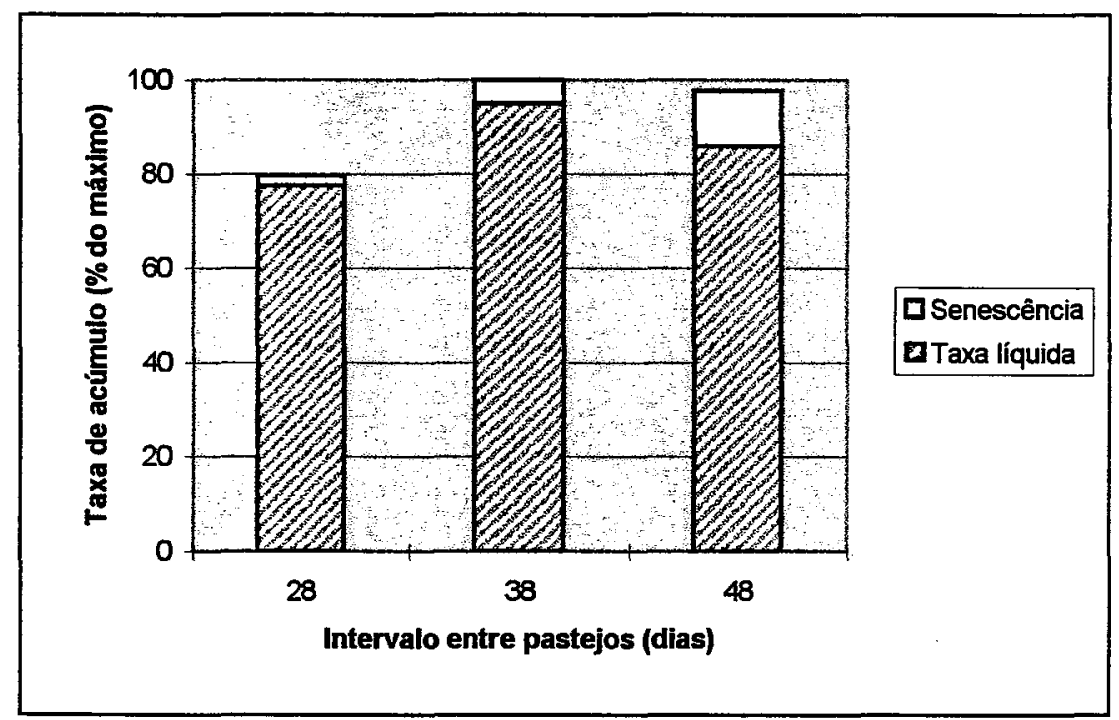

Figura 3: Taxa de acúmulo líquido e de senescência em abril/maio (estádio reprodutivo) para a) capim Mombaça e b)capim Tanzânia. 
As Figuras 3.a e 3.b representam o comportamento dos capim Mombaça e Tanzânia durante a fase reprodutiva (abril/maio). No capim Mombaça, a taxa de acúmulo líquido tendeu a diminuir e a de senescência a aumentar com o intervalo entre pastejos, sendo que com 48 dias praticamente já não havia mais produção líquida de forragem. No capim Tanzânia, o taxa de acúmulo líquido foi máxima com 38 dias, e depois tendeu a diminuir. A taxa de senescência, por sua vez, tendeu a aumentar, principalmente quando se passou de 38 para 48 dias.

De acordo com esses dados de taxa de acúmulo líquido e senescência, o período de descanso deve ser inferior a 28 dias para o capim Mombaça e menor que 38 para o capim Tanzânia. Períodos maiores que estes podem acarretar em queda de produção e aumento das perdas por senescência.

É importante lembrar, no entanto, que a taxa de alongamento foliar neste período diminuiu com o aumento intervalo entre pastejos, chegando a zero com 48 dias, devido ao florescimento (Tabelas 2 e 3). Isso significa que o acúmulo de forragem é reflexo do crescimento das hastes. As consequências deste fato sobre o manejo dos pastos será discutida mais adiante. 
a)

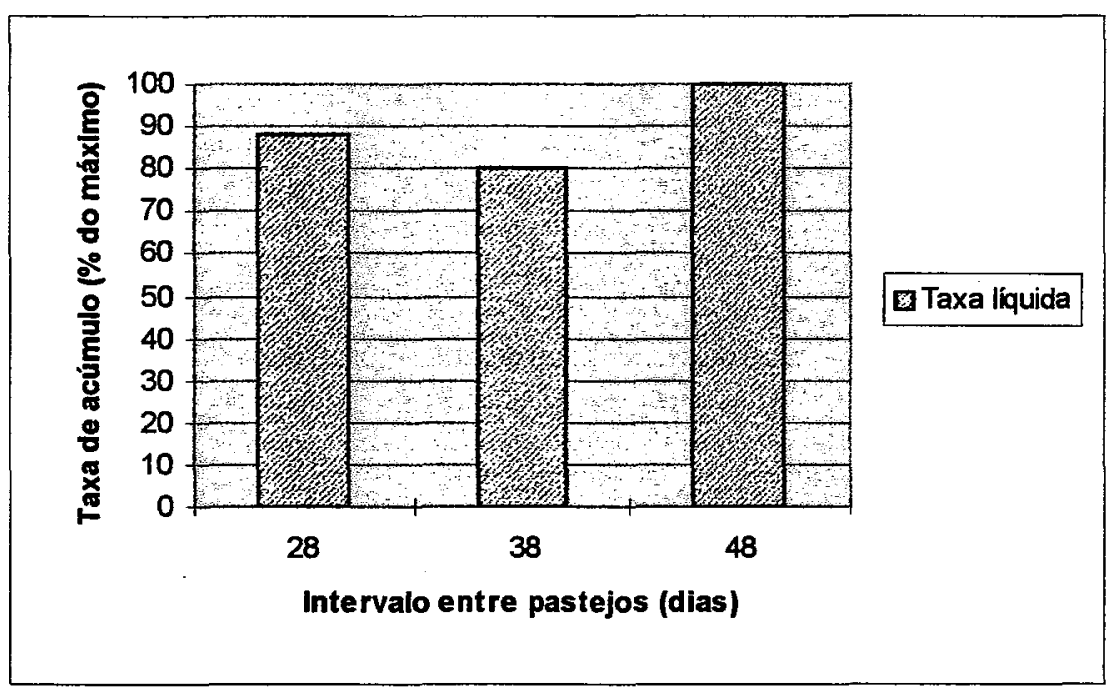

b)

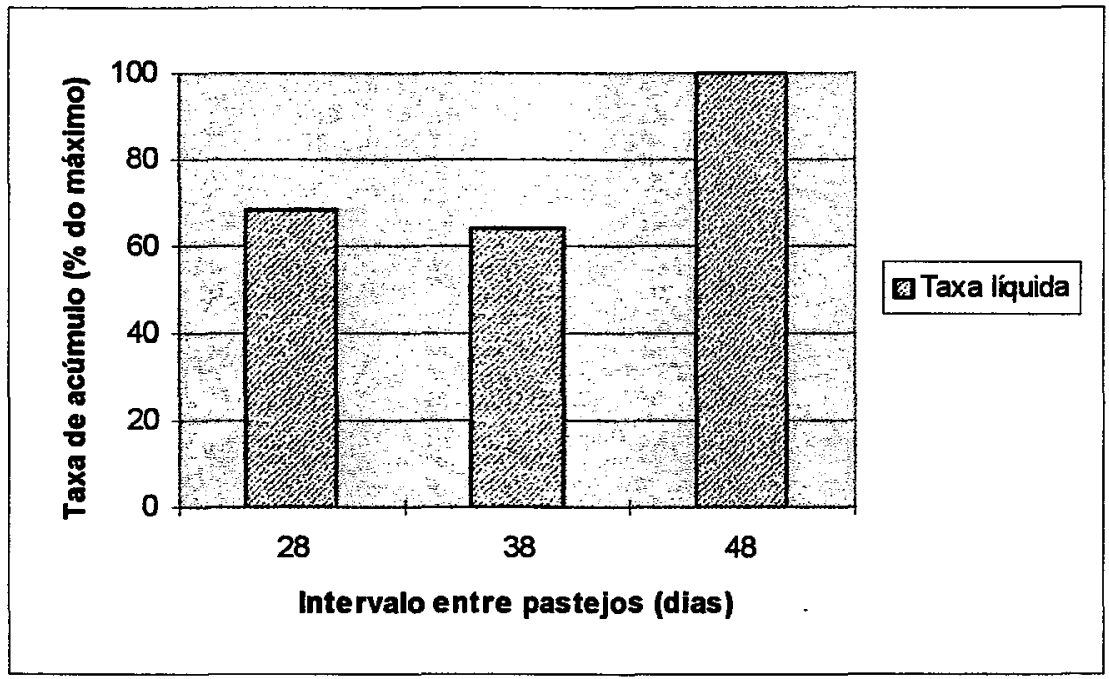

Figura 4: Taxa de acúmulo líquido em maio/setembro (estádio vegetativo) para a) capim Mombaça e b)capim Tanzânia 
No periodo de maio a setembro, o comportamento dos dois cultivares foi muito semelhante, sendo que a taxa de acúmulo tendeu a aumentar com o intervalo entre pastejos, praticamente não havendo senescência (Figuras 4.a e 4.b). Isso indica, que nesta época, os pastejos devem ser feitos com intervalos superiores a 48 dias.

Os resultados discutidos até agora mostram o comportamento das plantas durante o período de rebrota, porém é importante lembrar que, durante o pastejo, existem outras formas de perda que podem reduzir a eficiência do sistema de produção como um todo.

Hillesheim (1987) determinou que se perdia 49,35 kg/ha de matéria seca para cada centímetro de aumento na altura do capim elefante. Essa perda de forragem era decorrente da ação do trânsito dos animais sobre a planta forrageira, fazendo com que os perfilhos tombassem e ficassem mais sujeitos ao pisoteio. A Tabela 7 mostra que a altura, tanto do capim Mombaça quanto do capim Tanzânia, aumentou com o intervalo entre pastejos praticamente em todos os períodos de avaliação. Neste experimento as perdas fisicas não foram quantificadas, porém se observou que quando o pasto ficava muito alto, estas se tornavam bastante significativas. Isso ocorreu, principalmente, no período de novembro a maio. 
Tabela 7: Efeito do intervalo entre pastejos e do período de avaliação sobre a altura do pasto (cm) nos capins Mombaça e Tanzânia.

\begin{tabular}{|c|c|c|c|c|c|c|c|}
\hline \multirow{2}{*}{$\begin{array}{c}\text { Intervalo } \\
\text { entre } \\
\text { pastejos }\end{array}$} & \multicolumn{7}{|c|}{ Período } \\
\hline & $\begin{array}{c}14 / 11- \\
31 / 12 / 95\end{array}$ & $\begin{array}{c}1 / 1- \\
17 / 2 / 96\end{array}$ & $\begin{array}{l}18 / 2- \\
5 / 4 / 96\end{array}$ & $\begin{array}{c}6 / 4- \\
23 / 5 / 96\end{array}$ & $\begin{array}{c}24 / 5- \\
10 / 7 / 96\end{array}$ & $\begin{array}{c}11 / 7- \\
27 / 8 / 96\end{array}$ & $\begin{array}{c}28 / 8- \\
14 / 9 / 96\end{array}$ \\
\hline & \multicolumn{7}{|c|}{ Altura no capim Mombaça $(\mathrm{cm})^{1}$} \\
\hline 28 dias & $92,8^{\mathrm{Bb}}$ & $124,8^{\mathrm{Ca}}$ & $97,2^{\text {B b }}$ & $107,3^{\mathrm{Cab}}$ & $72,3^{\mathrm{Abc}}$ & $65,1^{A c}$ & $57,6^{\mathrm{Bc}}$ \\
\hline 38 dias & $92,9^{\mathrm{B} \mathrm{a}}$ & $154,5^{\mathrm{B} \mathrm{a}}$ & $146,6^{\mathrm{Aa}}$ & $134,0^{\mathrm{Ba}}$ & $86,4^{\mathrm{Ab}}$ & $83,4^{\mathrm{Ab}}$ & $82,1^{\mathrm{Ab}}$ \\
\hline \multirow[t]{2}{*}{48 dias } & $134,0^{\mathrm{Ac}}$ & $191,8^{\mathrm{Aa}}$ & $137,9^{\mathrm{Ac}}$ & $165,6^{\mathrm{Ab}}$ & $84,5^{\mathrm{Ad}}$ & $63,9^{\mathrm{Ad}}$ & $82,2^{\text {Ad }}$ \\
\hline & \multicolumn{7}{|c|}{ Altura no capim Tanzânia $(\mathrm{cm})^{1,2}$} \\
\hline 28 dias & $59,5^{\mathrm{B} \mathrm{b}}$ & $79,4^{\mathrm{Ca}}$ & $80,3^{\mathrm{Ca}}$ & $86,3^{\mathrm{Ba}}$ & $57,0^{\mathrm{B} \mathrm{bc}}$ & $57,3^{\mathrm{Abc}}$ & $49,3^{B c}$ \\
\hline 38 dias & $62,5^{\mathrm{Bc}}$ & $115,9^{\mathrm{Ba}}$ & $98,5^{\mathrm{Bb}}$ & $89,3^{\mathrm{Bb}}$ & $60,7^{\mathrm{Bcd}}$ & $52,3^{\mathrm{Ad}}$ & $61,4^{\mathrm{Acd}}$ \\
\hline 48 dias & $89,8^{\mathrm{Ac}}$ & $154,5^{\mathrm{Aa}}$ & $113,3^{A b}$ & $142,8^{\mathrm{Aa}}$ & $84,5^{\mathrm{Ac}}$ & $59,3^{\mathrm{Ad}}$ & $70,0^{\mathrm{Ad}}$ \\
\hline
\end{tabular}

${ }^{1}$ Médias seguidas pela mesma letra maiúscula na coluna e minúscula na linha, não diferem significativamente $(\mathrm{p}<0,05)$.

${ }^{2}$ Dados analisados segundo a transformação raiz quadrada. As médias foram re-transformadas.

Parsons et al. (1988), ressaltam a importância de se controlar a produção de hastes no pasto. A presença das hastes pode reduzir a eficiência do sistema de duas formas: limitando a capacidade de colheita da forragem pelo animal ou reduzindo o seu valor alimentar.

Trabalhos com plantas temperadas têm demonstrado que a profundidade do horizonte de pastejo é limitada pela altura das hastes (Barthram \& Grant, 1984; Flores et al., 1993). Nas Tabelas 8 e 9 observa-se que o comprimento das hastes aumentou nas desfolhas menos frequentes. Em plantas tropicais, praticamente não existem informações a respeito do efeito da altura das hastes sobre o comportamento dos animais durante o pastejo. Este trabalho mostra a necessidade de se estudar melhor essa característica a fim de determinar se a extensão do período de descanso até o momento de máxima taxa de acúmulo não irá implicar na redução da eficiência de pastejo. 
Tabela 8: Efeito do intervalo entre pastejos e do período de avaliação sobre o comprimento das hastes $(\mathrm{cm})$ no capim Mombaça.

\begin{tabular}{|c|c|c|c|c|c|c|c|}
\hline \multirow{3}{*}{$\begin{array}{c}\text { Intervalo } \\
\text { entre } \\
\text { pastejos }\end{array}$} & \multicolumn{7}{|c|}{ Período } \\
\hline & $14 / 11-$ & $1 / 1-$ & $18 / 2-$ & $6 / 4-$ & $24 / 5$ & $11 / 7$ & $28 / 8-$ \\
\hline & $31 / 12 / 95$ & $17 / 2 / 96$ & $5 / 4 / 96$ & $23 / 5 / 96$ & $10 / 7 / 96$ & $27 / 8 / 96$ & $14 / 9 / 96$ \\
\hline & \multicolumn{7}{|c|}{ Comprimento das hastes $(\mathrm{cm})^{1,2}$} \\
\hline 28 dias & $20,5^{\mathrm{Bc}}$ & $33,6^{\mathrm{Bb}}$ & $44,8^{\mathrm{B} \mathrm{a}}$ & $50,3^{\mathrm{Ca}}$ & $18,8^{\mathrm{Bc}}$ & $14,1^{\mathrm{Bd}}$ & $14,7^{\mathrm{Bd}}$ \\
\hline 38 dias & $20,5^{\mathrm{B} \mathrm{c}}$ & $50,1^{\mathrm{Ab}}$ & $58,6^{\mathrm{Ab}}$ & $72,2^{\mathrm{Ba}}$ & $17,5^{\mathrm{B} \mathrm{cd}}$ & $16,2^{\mathrm{ABd}}$ & $17,1 \mathrm{AB} \mathrm{d}$ \\
\hline 48 dias & $31,6^{\mathrm{Ad}}$ & $51,0^{A c}$ & $62,0^{\mathrm{Ab}}$ & $169,5^{\mathrm{Aa}}$ & $27,8^{\mathrm{Ad}}$ & $16,9^{\mathrm{Ae}}$ & $19,2^{\mathrm{Ae}}$ \\
\hline
\end{tabular}

Tabela 9: Efeito do intervalo entre pastejos e do período de avaliação sobre o comprimento das hastes $(\mathrm{cm})$ no capim Tanzânia.

\begin{tabular}{|c|c|c|c|c|c|c|c|}
\hline \multirow{3}{*}{$\begin{array}{c}\text { Intervalo } \\
\text { entre } \\
\text { pastejos }\end{array}$} & \multicolumn{7}{|c|}{ Período } \\
\hline & 14/11- & $1 / 1-$ & $18 / 2-$ & $6 / 4-$ & $24 / 5-$ & $11 / 7-$ & $28 / 8-$ \\
\hline & $31 / 12 / 95$ & $17 / 2 / 96$ & $5 / 4 / 96$ & $23 / 5 / 96$ & $10 / 7 / 96$ & $27 / 8 / 96$ & $14 / 9 / 96$ \\
\hline & \multicolumn{7}{|c|}{ Comprimento das hastes $(\mathrm{cm})^{1,2}$} \\
\hline 28 dias & $18,6^{\mathrm{Bd}}$ & $29,4^{\mathrm{Cc}}$ & $36,3^{\mathrm{B} \mathrm{b}}$ & $47,9^{\mathrm{Ca}}$ & $24,1^{\mathrm{Bc}}$ & $15,2^{A d e}$ & $14,9^{\mathrm{Be}}$ \\
\hline 38 dias & $21,7^{\mathrm{Bd}}$ & $44,4^{\mathrm{Bc}}$ & $37,9^{\mathrm{B} \mathrm{b}}$ & $60,0^{\mathrm{Ba}}$ & $27,7^{\mathrm{AB} c}$ & $14,5^{\mathrm{Ae}}$ & $16,1^{\mathrm{AB} \mathrm{e}}$ \\
\hline 48 dias & $29,0^{\text {Ac }}$ & $59,9^{\mathrm{Ab}}$ & $50,5^{\mathrm{Ab}}$ & $148,6^{\mathrm{Aa}}$ & $31,8^{A c}$ & $16,9^{\mathrm{Ad}}$ & $19,6^{\mathrm{Ad}}$ \\
\hline
\end{tabular}

${ }^{1}$ Médias seguidas pela mesma letra maiúscula na coluna e minúscula na linha, não diferem significativamente $(\mathrm{p}<0,05)$.

${ }^{2}$ Dados analisados segundo a transformação logaritmo natural. As médias foram re-transformadas.

Algumas pessoas podem estranhar que, de modo geral, a taxa de alongamento do capim Tanzânia tenha apresentado uma tendência de ser maior que a do capim 
Mombaça, enquanto no comprimento das hastes se observa o contrário. É preciso lembrar, no entanto, que a taxa de alongamento foi avaliada apenas durante alguns dias antes do pastejo (sete no verão e nove no inverno), ou seja, não é possível saber se antes deste período a taxa de alongamento do capim Mombaça era maior e nem se o comprimento das suas hastes após o pastejo anterior era diferente.

$\mathrm{O}$ valor nutritivo das hastes cai mais rapidamente que o das folhas com o aumento da idade do capim (Andrade, 1987; Singh, 1995). Além disso, o tempo de retenção das folhas no trato digestivo, inferior ao das hastes, permite que o consumo de folhas seja maior mesmo quando os níveis de digestibilidade, fibra em detergente neutro, fibra em detergente ácido e lignina são semelhantes (Poppi et al., 1981; Forbes \& Coleman, 1993).

As Tabelas 10, 11 e 12 mostram os valores de relação folha:haste para os capins Tanzânia e Mombaça, entre novembro e maio. Nos meses de maio a setembro essa característica não foi avaliada.

Tabela 10: Efeito do intervalo entre pastejos e do período na relação folha:haste do capim Tanzânia.

\begin{tabular}{ccccc}
\hline Intervalo & \multicolumn{4}{c}{ Período } \\
\cline { 2 - 5 } entre pastejos & $14 / 11-31 / 12 / 95$ & $1 / 1-17 / 2 / 96$ & $18 / 2-5 / 4 / 96$ & $6 / 4-23 / 5 / 96$ \\
\hline & & \multicolumn{4}{c}{ Relação folha:haste } \\
28 dias & $1,39^{\mathrm{B} \mathrm{a}}$ & $1,17^{\mathrm{Aab}}$ & $1,42^{\mathrm{Aa}}$ & $1,00^{\mathrm{Ab}}$ \\
38 dias & $1,61^{\mathrm{AB} \mathrm{a}}$ & $1,10^{\mathrm{Ab}}$ & $1,10^{\mathrm{Bb}}$ & $0,76^{\mathrm{Bc}}$ \\
48 dias & $1,89^{\mathrm{Aa}}$ & $1,05^{\mathrm{Ab}}$ & $1,02^{\mathrm{B} \mathrm{b}}$ & $0,39^{\mathrm{Cc}}$ \\
\hline
\end{tabular}

${ }^{1}$ Médias seguidas pela mesma letra maiúscula na coluna e minúscula na linha, não diferem significativamente $(\mathrm{p}<0,05)$.

${ }^{2}$ Os dados foram analisados segunda a transformação raiz quadrada recíproca. As médias foram retransformadas. 
No capim Tanzânia houve interação entre intervalo entre pastejos e período do ano para a variável relação folha:haste (Tabela 10). Em novembro/dezembro, a participação das folhas aumentou com o intervalo entre cortes, em janeiro/fevereiro se manteve constante e de fevereiro a maio diminuiu.

Tabela 11: Efeito do intervalo entre pastejos sobre a relação folha:haste do capim Mombaça.

Intervalo entre pastejos (dias) 28 38 48
Relação folha:haste

$1,32^{\mathrm{a}}$

$$
1,16^{\mathrm{ab}}
$$

$0,99^{\mathrm{b}}$

${ }^{1}$ Médias seguidas da mesma letra nas colunas não diferem significativamente $(\mathrm{p}<0,05)$.

${ }^{2}$ Os dados foram analisados segunda a transformação logarítmica decimal. As médias foram re-transformadas.

A relação folha:haste do capim Mombaça caiu com o aumento do intervalo entre pastejos de 28 para 48 dias. Com 38 dias ela foi intermediária (Tabela 11). A redução da relação folha:haste com o aumento da idade foi relatada por Andrade (1987) para os cultivares Colonião e Tobiatã e por Pinto et al. (1994) para o cultivar Guiné.

Tabela 12: Efeito do período do ano sobre a relação folha:haste do capim Mombaça.

\begin{tabular}{cc}
\hline Período & Relação folha:haste $^{1,2}$ \\
\hline $14 / 11$ a 31/12/1995 & $1,87^{\mathrm{a}}$ \\
$1 / 1$ a $17 / 2 / 1996$ & $1,14^{\mathrm{b}}$ \\
$18 / 2$ a $5 / 4 / 1996$ & $1,13^{\mathrm{b}}$ \\
$6 / 4$ a $23 / 5 / 1996$ & $0,71^{\mathrm{c}}$
\end{tabular}

\footnotetext{
${ }^{1}$ Médias seguidas da mesma letra nas colunas não diferem significativamente $(\mathrm{p}<0,05)$.
}

${ }^{2}$ Os dados foram analisados segunda a transformação logarítmica decimal. As médias foram re-transformadas. 
Para os dois capins foi observado que, de modo geral, a participação das folhas (Tabela 10 e 12) foi maior no primeiro período (novembro/dezembro) e menor no quarto (abril/maio), sendo intermediário no segundo (janeiro/fevereiro) e terceiro (fevereiro/março). A única exceção foi o capim Tanzânia cortado com 28 dias, onde não houve diferença entre os três primeiros períodos, nem entre o segundo e o quarto. A baixa porcentagem de folhas em abril/maio é decorrente da predominância de perfilhos reprodutivos neste período.

Para Pinto et al. (1994), o valor limite para a relação folha:haste seria 1,0. No presente estudo, tanto para o capim Tanzânia como para o capim Mombaça, os maiores valores de relação folha:haste foram obtidos no período de novembro/dezembro, porém estes nunca foram superiores a 1,8. Entre janeiro, fevereiro e março, a participação das hastes aumentou, e a relação folha:haste ficou entre 1,02 e 1,18 (exceto para o capim Tanzânia com 28 dias). Já no período de abril/maio, os valores foram iguais ou inferiores a 1,0 .

Apesar do valor limite sugerido por Pinto et al. (1994) ser arbitrário, a relação folha:haste dos capins Tanzânia e Mombaça, nas condições estudadas, foi inegavelmente baixa, o que sugere levar-se em consideração esta característica para a determinação do período de descanso. Ou seja, em algumas épocas do ano, será mais importante controlar a participação das hastes na produção do que maximizar a taxa de acúmulo líquido ou reduzir as perdas por senescência.

Para isso, é necessário se estudar o efeito da relação folha:haste sobre o consumo e qualidade da forragem. Essa não é uma tarefa fácil, pois o real efeito da relação folha:haste sobre o desempenho animal vai depender de fatores como pressão de pastejo e resíduo pós pastejo. De qualquer forma, já é possível afirmar que, durante a fase reprodutiva, os intervalos entre pastejos devem ser inferiores a 28 dias, mesmo no caso do capim Tanzânia, onde os níveis de taxa de acúmulo líquido se mantêm elevados até 48 dias de descanso.

No caso do azevém, após se atingir a máxima taxa de acúmulo líquido, a senescência aumenta rapidamente, até que as taxas de crescimento e morte se equilibram. A partir 
daí, não há mais acúmulo líquido de forragem (Davies, 1971). Para os capins Mombaça e Tanzânia, apesar do aumento da senescência nos períodos entre novembro e maio, o equilíbrio entre morte e crescimento de tecidos não foi atingido em nenhuma época do ano, o que se refletiu no aumento do comprimento total de folhas verdes(Tabelas $13 \mathrm{e}$ 14) e no comprimento das hastes ( Tabelas 8 e 9) com o aumento do intervalo entre pastejos.

Tabela 13: Efeito do intervalo entre pastejos e do período de avaliação sobre o comprimento total de folhas verdes $(\mathrm{cm})$ no capim Mombaça.

\begin{tabular}{|c|c|c|c|c|c|c|c|}
\hline \multirow{3}{*}{$\begin{array}{c}\text { Intervalo } \\
\text { entre } \\
\text { pastejos }\end{array}$} & \multicolumn{7}{|c|}{ Período } \\
\hline & $14 / 11-$ & $1 / 1-$ & $18 / 2-$ & $6 / 4-$ & $24 / 5$ & $11 / 7-$ & $28 / 8$ \\
\hline & $31 / 12 / 95$ & $17 / 2 / 96$ & $5 / 4 / 96$ & $23 / 5 / 96$ & $10 / 7 / 96$ & $27 / 8 / 96$ & $14 / 9 / 96$ \\
\hline & \multicolumn{7}{|c|}{ Comprimento foliar $(\mathrm{cm})^{1}$} \\
\hline 28 dias & $177,8^{\text {B d }}$ & $258,1^{\mathrm{Cb}}$ & $322,6^{\mathrm{Ba}}$ & $215,0^{\mathrm{Cc}}$ & $116,3^{A d}$ & $118,3^{\mathrm{Ad}}$ & $111,3^{\mathrm{Bd}}$ \\
\hline 38 dias & $186,2^{\text {B d }}$ & $384,1^{\mathrm{Aa}}$ & $347,7^{\text {В b }}$ & $247,4^{\mathrm{Bc}}$ & $114,7^{\text {Af }}$ & $130,3^{\text {Af }}$ & $157,8^{\mathrm{Ae}}$ \\
\hline 48 dias & $271,6^{\mathrm{Ac}}$ & $352,3^{\mathrm{B} \mathrm{b}}$ & $430,8^{\mathrm{Aa}}$ & $330,0^{\mathrm{Ab}}$ & $131,7^{\mathrm{Ae}}$ & $139,2^{\mathrm{Ae}}$ & $177,5^{\mathrm{Ad}}$ \\
\hline
\end{tabular}

${ }^{1}$ Médias seguidas pela mesma letra maiúscula na coluna e minúscula na linha, não diferem significativamente $(p<0,05)$.

Tabela 14: Efeito do intervalo entre pastejos e do período de avaliação sobre o comprimento total de folhas verdes $(\mathrm{cm})$ no capim Tanzânia.

\begin{tabular}{|c|c|c|c|c|c|c|c|}
\hline \multirow{3}{*}{$\begin{array}{c}\text { Intervalo } \\
\text { entre } \\
\text { pastejos }\end{array}$} & \multicolumn{7}{|c|}{ Período } \\
\hline & $14 / 11-$ & $1 / 1-$ & $18 / 2-$ & $6 / 4-$ & $24 / 5$ & $11 / 7-$ & $28 / 8$ \\
\hline & $31 / 12 / 95$ & $17 / 2 / 96$ & $5 / 4 / 96$ & $23 / 5 / 96$ & $10 / 7 / 96$ & $27 / 8 / 96$ & $14 / 9 / 96$ \\
\hline & \multicolumn{7}{|c|}{ Comprimento foliar (cm) ${ }^{1,2}$} \\
\hline 28 dias & $159,1^{\mathrm{Cc}}$ & $190,5^{\mathrm{Cb}}$ & $267,5^{\mathrm{Ba}}$ & $166,1^{\mathrm{Co}}$ & $94,9^{\mathrm{Be}}$ & $108,6^{\mathrm{Bd}}$ & $109,2^{\mathrm{Cd}}$ \\
\hline 38 dias & $197,1^{\mathrm{B} \mathrm{b}}$ & $293,6^{\mathrm{Ba}}$ & $262,3^{\mathrm{Ba}}$ & $191,2^{\mathrm{B} \mathrm{b}}$ & $108,9^{\mathrm{Ad}}$ & $112,9^{\mathrm{B} \mathrm{cd}}$ & $126,4^{\mathrm{Bc}}$ \\
\hline 48 dias & $240,5^{\mathrm{Ab}}$ & $358,8^{\mathrm{Aa}}$ & $340,5^{\mathrm{Aa}}$ & $264,3^{A b}$ & $102,0^{\mathrm{Ae}}$ & $136,0^{\mathrm{Ad}}$ & $172,7^{\mathrm{Ac}}$ \\
\hline
\end{tabular}


O aumento do comprimento foliar verde foi atribuído ao maior comprimento das folhas individualmente. Apesar de em alguns períodos o número de folhas ter aumentado com o intervalo entre pastejos, as diferenças foram muito pequenas (Tabelas 15 e 16). Essa conclusão é confirmada pelos dados de Gomide \& Gomide (1996). Esses autores determinaram que o comprimento médio $(\mathrm{cm})$ das 13 primeiras folhas no capim Mombaça se definia pela equação $\mathrm{Y}=-7,26+5,68 \mathrm{~F}(\mathrm{r}=0,96)$, onde $\mathrm{F}$ indica o nível de inserção.

Tabela 15: Efeito do intervalo entre pastejos e do período de avaliação sobre o número de folhas vivas no capim Mombaça.

\begin{tabular}{cccccccc}
\hline Intervalo & \multicolumn{7}{c}{ Período } \\
\cline { 2 - 7 } entre & $14 / 11-$ & $1 / 1-$ & $18 / 2-$ & $6 / 4-$ & $24 / 5-$ & $11 / 7-$ & $28 / 8-$ \\
pastejos & $31 / 12 / 95$ & $17 / 2 / 96$ & $5 / 4 / 96$ & $23 / 5 / 96$ & $10 / 7 / 96$ & $27 / 8 / 96$ & $14 / 9 / 96$ \\
\hline \multirow{7}{*}{28 dias } & $4,4^{\mathrm{Bc}}$ & $5,3^{\mathrm{ABa}}$ & $5,6^{\mathrm{Ba}}$ & $5,6^{\mathrm{Ba}}$ & $4,7^{\mathrm{A} \mathrm{bc}}$ & $4,9^{\mathrm{Ab}}$ & $4,9^{\mathrm{B} \mathrm{b}}$ \\
38 dias & $4,7^{\mathrm{AB} \mathrm{c}}$ & $5,6^{\mathrm{Aab}}$ & $6,1^{\mathrm{Aa}}$ & $5,4^{\mathrm{B} \mathrm{b}}$ & $4,5^{\mathrm{Ac}}$ & $5,2^{\mathrm{Ab}}$ & $5,8^{\mathrm{Aa}}$ \\
48 dias & $5,0^{\mathrm{Ac}}$ & $5,1^{\mathrm{Bc}}$ & $6,1^{\mathrm{Ab}}$ & $6,7^{\mathrm{Aa}}$ & $4,7^{\mathrm{Ac}}$ & $5,0^{\mathrm{Ac}}$ & $6,0^{\mathrm{Ab}}$ \\
\hline
\end{tabular}

Tabela 16: Efeito do intervalo entre pastejos e do período de avaliação sobre o número de folhas vivas no capim Tanzânia.

\begin{tabular}{cccccccc}
\hline Intervalo & \multicolumn{7}{c}{ Período } \\
\cline { 2 - 7 } $\begin{array}{c}\text { entre } \\
\text { pastejos }\end{array}$ & $14 / 11-$ & $1 / 1-$ & $18 / 2-$ & $6 / 4-$ & $24 / 5-$ & $11 / 7-$ & $28 / 8-$ \\
& $31 / 12 / 95$ & $17 / 2 / 96$ & $5 / 4 / 96$ & $23 / 5 / 96$ & $10 / 7 / 96$ & $27 / 8 / 96$ & $14 / 9 / 96$ \\
\hline \multirow{7}{*}{28 dias } & $5,0^{\mathrm{A} \mathrm{bc}}$ & $5,1^{\mathrm{Ab}}$ & $5,5^{\mathrm{Aa}}$ & $5,5^{\mathrm{Ba}}$ & $4,6^{\mathrm{Ac}}$ & $4,9^{\mathrm{Abc}}$ & $5,0^{\mathrm{Bb}}$ \\
38 dias & $5,1^{\mathrm{A} \mathrm{bc}}$ & $5,3^{\mathrm{Ab}}$ & $5,8^{\mathrm{Aa}}$ & $4,9^{\mathrm{Cc}}$ & $4,8^{\mathrm{Ac}}$ & $4,9^{\mathrm{Ac}}$ & $5,5^{\mathrm{Abb}}$ \\
48 dias & $5,1^{\mathrm{Acd}}$ & $5,5^{\mathrm{Abc}}$ & $5,5^{\mathrm{Abc}}$ & $6,1^{\mathrm{Aa}}$ & $4,5^{\mathrm{Ae}}$ & $5,0^{\mathrm{Ad}}$ & $5,6^{\mathrm{Ab}}$ \\
\hline
\end{tabular}

${ }^{1}$ Médias seguidas pela mesma letra maiúscula na coluna e minúscula na linha, não diferem significativamente $(p<0,05)$. 
Segundo Lemaire \& Chapman (1996), como o número de folhas vivas por perfilho é constante, o equilíbrio entre produção e senescência só será atingido quando as folhas que estão senescendo apresentarem tamanho semelhante ao das que estão crescendo. Em azevém isso se dá pouco depois do aparecimento de 6 folhas. Nos capins Tanzânia e Mombaça ainda não foi determinado como esse equilíbrio é atingido, porém, considerando que os princípios são os mesmos do azevém e usando as informações de Gomide \& Gomide (1996), é possível prever que isto só irá ocorrer com mais de 100 dias de crescimento. ${ }^{3}$

Esse fato proporciona uma certa flexibilidade ao manejo destes capins, pois significa que mesmo com períodos de descanso muito longos, ainda haverá acúmulo líquido de forragem, apesar da redução da produção e/ou no potencial de utilização da forragem produzida. Isso é importante para os sistemas menos intensivos de produção, onde a capacidade de controle do intervalo entre cortes é menor.

Nos últimos anos, tem sido divulgado no Brasil o conceito de que o intervalo entre desfolhas de um pasto pode ser calculado pelo filocrono e pelo número de folhas que um perfilho consegue manter (Corsi, 1992; Corsi et al., 1994; Gomide, 1997). Por esse motivo, diversos trabalhos vêm sendo realizados com o objetivo de determinar esses valores em espécies forrageiras de interesse comercial (Barbosa et al., 1996; Gomide \& Gomide, 1996; Carvalho \& Damasceno, 1996).

No entanto, é preciso lembrar que o número de folhas por perfilho e o filocrono não constituem por si sós um princípio de manejo. A idéia da adoção desses valores para nortear o manejo dos pastos surgiu das recomendações que têm sido feitas para o azevém. Neste capim, a desfolha deve ser feita quando se completar a expansão de três folhas, que é o número máximo de folhas que um perfilho consegue manter. Essa recomendação, no entanto, se baseia em que, após o aparecimento da terceira folha, a

\footnotetext{
${ }^{3}$ Considerando uma média de 5 folhas vivas para o Capim Mombaça, a $13^{\mathrm{a}}$ folha irá senescer após o aparecimento de 18 folhas. A taxa de aparecimento de folhas determinada por GOMIDE \& GOMIDE (1996) foi de 6,6 dias/folha, logo a $18^{\mathrm{a}}$ folha só deverá aparecer aos 118,8 dias de crescimento. Como até a $13^{\mathrm{a}}$ folha ainda havia correlação entre nível de inserção e comprimento foliar, o equilibrio entre morte e senescência só ocorrerá após 118 dias de crescimento.
} 
taxa de senescência aumenta rapidamente, até atingir um equilibrio entre produção e morte de tecidos (Davies, 1971; Fulkerson \& Slack, 1994; Fulkerson \& Slack, 1995).

Fica claro, portanto, que antes se assumir que um pasto qualquer deve ser cortado após a completa expansão de um determinado número de folhas, é preciso saber qual o objetivo que se deseja atingir (maximizar a taxa de acúmulo líquido, minimizar a senescência, controlar o crescimento das hastes, etc) e em que estádio de desenvolvimento isso será concretizado.

Neste experimento não foi possível determinar o filocrono, pois os períodos de avaliação adotados ( 7 e 9 dias para verão e inverno, respectivamente) não foram suficientes para que ocorresse o aparecimento de duas folhas consecutivas em todos os perfilhos. No entanto, algumas questões com relação ao uso da taxa de aparecimento de folhas no manejo de pastagens foram levantadas.

Como se verificou ao longo da discussão, o tamanho das folhas nos capins Mombaça e Tanzânia aumenta com o nível de inserção. É de se esperar, portanto, que a taxa de aparecimento, a longevidade, a taxa e o tempo de alongamento também mudem. Wilson (1976) observou que, em Panicum maximum var. Trichoglume, as folhas de nível de inserção mais elevado se desenvolveram mais lentamente e permaneceram verdes por mais tempo. Gomide \& Gomide (1996) observaram que no capim Mombaça o tempo e a taxa de alongamento mudava com o nivel de inserção da folha.

Além disso, não se sabe se o corte do perfilho interfere em suas características morfogenéticas. Grant et al. (1981), por exemplo, encontraram uma correlação positiva entre o comprimento do pseudocaule e o tamanho das folhas que emergiam por ele, quando plantas de azevém perene eram cortadas a diferentes alturas.

Em áreas de pastagem são encontrados perfilhos produzidos em diferentes épocas. Segundo Barbosa et al. (1996), na rebrota do capim Mombaça havia um maior número de perfilhos remanescentes que novos e no capim Tanzânia não houve diferença entre as duas categorias. Esses autores observaram também diferenças entre as estações do ano. No inverno havia maior número de perfilhos novos, enquanto na primavera e outono ocorreu o contrário. No verão não houve diferença entre as duas categorias de perfilhos. 
Essa variabilidade na população de perfilhos em termos de estádio de desenvolvimento, aliada às diferenças nas características morfogenéticas das plantas nos diferentes estádios limitam a adoção de uma taxa média de aparecimento de folhas. Talvez o ideal seja determinar qual a categoria de perfilhos que é responsável pela maior parte da produção e basear o manejo no comportamento destes. 


\section{5) CONCLUSÕES}

O presente experimento permite concluir que o cultivar Mombaça deve ser pastejado com menos de 28 dias no período de novembro a maio e com mais de 48 dias entre maio e setembro. Já o cultivar Tanzânia deve ser pastejado com menos de 38 dias entre novembro e abril, com menos de 28 durante a fase reprodutiva (abril/maio) e com mais de 48 entre maio e setembro. A extensão dos períodos de descanso pode reduzir a produção ou o potencial de utilização da forragem produzida, porém ainda continuará havendo acúmulo líquido de forragem. Essa verificação importa, sobretudo aos sistemas de manejo menos intensivos, onde o controle do intervalo entre pastejos é menos rigoroso.

São necessários mais estudos sobre os efeitos: da altura das plantas na pastagem sobre as perdas fisicas de forragem; da altura das hastes sobre o comportamento de pastejo dos animais; e da relação folha:haste sobre o valor alimentar da forragem, levando-se em consideração a pressão de pastejo e o resíduo pós-pastejo.

$\mathrm{O}$ uso do filocrono no manejo de pastagens ainda apresenta muitas limitações, principalmente devido à variabilidade na população de perfilhos que constituem o pasto. Sugere-se determinar qual a categoria de perfilhos responsável pela maior parte da produção e basear o manejo no comportamento desta. 


\section{6) REFERÊNCIA BIBLIOGRÁFICAS}

ANDRADE, J.B. Estudo comparativo de 3 capins da espécie Panicum maximum Jacq. (colonião, tobiatã e K-187-B). Piracicaba, 1987. Dissertação (M.S.) - Escola Superior de Agricultura "Luiz de Queiroz"/USP.

ANSLOW, R.C. The rate of appearance of leaves on tillers of the gramineae. Herbage Abstracts, v.36, n.3, p.149-155, 1966.

ARNOTT, R.A. \& RYLE, G.J.A. Leaf surface expansion on the main axes of white and red clovers. Grass and Forage Science, v.37, p.227-233, 1982.

AUDA, H.; BLASER, R.E.; BROWN, R.H. Tillering and carbohydrate contents of orchardgrass as influenced by environmental factors. Crop Science, v.6, p.139$143,1966$.

BAKER, D.J.; CHU, A.C.P.; KORTE, C.J. Ryegrass herbage yield components and their response to water deficit stress. In: INTERNATIONAL GRASSLAND CONGRESS, 16., França, 1989. Proceedings. França: Association Francaise pour la Producion Fourragere, Centre Nacional de Recherche Agronomique, 1989. p.503-504.

BAKER, A.M.; YOUNGER, A. Factors affecting the leaf extension rate of perennial ryegrass in spring. Grass and Forage Science, v.42, p.381-390, 1987. 
BARBOSA, M.A.A.F.; DAMASCENO, J.C.; CECATO, U.; SAKAGUTI, E.S. Estudo de perfilhamento em 4 cultivares de Panicum maximum Jacq. Submetidos à duas alturas de corte. In: REUNIÃO ANUAL DA SOCIEDADE BRASILEIRA DE ZOOTECNIA, 33, Fortaleza, 1996, Anais. Fortaleza:SBZ, 1996. p.109-111.

BARTHRAM, G.T. \& GRANT, S.A. Defoliation of ryegrass-dominated swards by sheep. Grass and Forage Science, v.39, p.211-219, 1984.

BIRCHAM, J.S. \& HODGSON, J. The influence of sward condition on rates of herbage growth and senescence in mixed swards under continuous stocking management. Grass and Forage Science, v.38, p.323-331, 1983.

BITTMAN, S.; SIMPSON, G.M.; MIR, Z. Effect of drought on leaf senescence and forage quality of three temperate grasses. In: INTERNATIONAL GRASSLAND CONGRESS, 15., Japão, 1985. Proceedings. Japão: Science Council of Japan and Japanese Society of Grassland Science, 1985. p. 360-362.

CALVIÈRE, I.; DURU, M. Leaf appearance and senescence patterns of some pasture species. Grass and Forage Science, v.50, p.447-451, 1995.

CARVALHO, D.D. \& DAMASCENO, J.C. Aspectos fisiológicos do Capim -Elefante cv. Roxo de Botucatu. 1. Taxa de aparecimento, expansão e senescência de folhas. In: REUNIÃo ANUAL DA SOCIEDADE BRASILEIRA DE ZOOTECNIA, 33., Fortaleza,1996, Anais. Fortaleza, SBZ, 1996. p.4-6.

CASAL, J.J.; SANCHEZ, R.A.; GIBSON, D. The significance of changes in the red/farred ratio, associated with either neighbour plants or twilight, for tillering in Lolium multiflorum Lam. New Phytologist, v.116, p.565-572, 1990. 
CECATO, U.; MARCO, A.A.F.B; SAKAGUTI, E.S.; DAMASCENO, J.C.; SUZUKI, E.; MEURER, F. Avaliação de cultivares de Panicum maximum Jacq. In: REUNIÃO ANUAL DA SOCIEDADE BRASILEIRA DE ZOOTECNIA, 34., Fortaleza, 1996. Anais. Fortaleza, SBZ, 1996. p.403-406

CHAPMAM, D.F; CLARK, D.A.; LAND, C.A.; DYMOCK, N. Leaf and tiller growth of Lolium perenne and Agrostis spp. and leaf appearance rates of Trifolium repens in set-stocked and rotationally grazed hill pastures. New Zealand Journal of Agricultural Research, v.26, p.159-168, 1983.

COLLINS, R.P.; JONES, M.B. The effects of temperature on leaf growth in Cyperus longus, a temperate $\mathrm{C}_{4}$ species. Annals of Botany, v.61, p.355-362, 1988.

CORSI, M. Manejo do capim elefante sob pastejo. In: SIMPÓSIO SOBRE MANEJO DA PASTAGEM, 10., Piracicaba, 1992. Anais. Piracicaba, FEALQ, 1992. p.143-167.

CORSI, M.; BALSALOBRE, M.A.A.; SANTOS, P.M.; SILVA, S.C. Bases para o estabelecimento do manejo de pastagens de braquiária. In: SIMPÓSIO SOBRE MANEJO DA PASTAGEM, 11., Piracicaba, 1994. Anais. Piracicaba, FEALQ, 1994. p.249-266.

COSTA, C.; FAVORETTO, V.; MALHEIROS, E.B. Estudo da variação na estrutura da vegetação de duas cultivares de Panicum maximum Jacq. (colonião e tobiatã) submetidas a diferentes tipos de manejo. 1. Produção e densidade de perfilhos e de matéria seca. Pesquisa Agropecuária Brasileira, v.27, n.1, p.131-142, 1992. 
COUGHENOUR, M.B.; McNAUGHTON, S.J.; WALLACE, L.L. Responses of an african tall-grass (Hyparrhenia filipendula stapf.) to defoliation and limitations of water and nitrogen. Oecologia, v.68, p.80-86, 1985.

CRAUFURD, P.Q.; SUBEDI, M.; SUMMERFIELD, R.J. Leaf appearance in cowpea: effects of temperature and photoperiod. Crop Science, v.37, p.167-171, 1997.

DALE, J.E. Some effects of temperature and irradiance on growth of the first four leaves of wheat, Triticum aestivum. Annals of Botany, v.50, p.851-858, 1982.

DALE, J.E. How do leaves grow? Advances in cell and molecular biology are unraveling some of the mysteries of leaf development. Bioscience, v.42, n.6, p.423$432,1992$.

DAVIES, A. Changes in growth rate and morphology of perennial ryegrass swards at high and low nitrogen levels. Journal of Agricultural Science, v.77, p.123-134, 1971.

DAVIES, A. Tissue turnover in the sward. In. DAVIES, A.; BAKER, R.D.; GRANT, S.A.; LAIDLAW, A.S. (Ed.) Sward Measurement Handbook. Reading: The British Grassland Society, 1993. cap.9, p.183-216.

DAVIES, A.; ELEANOR EVANS, M.; POLLOCK, C.J. Influence of date of tiller origin on leaf extension rates in perennial and italian ryegrass at $15^{\circ} \mathrm{C}$ in relation to flowering propensity and carbohydrate status. Annals of Botany, v.63, n.377$384,1989$. 
DEINUM, B.; SULASTRI, R.D.; ZEINAB, M.H.J.; MAASSEN, A. Effects of light intensity on growth, anatomy and forage quality of two tropical grasses (Brachiaria brizantha and Panicum maximum var. trichoglume). Netherlands Journal of Agricultural Science, v.44, p.111-124, 1996.

DIAS FILHO, M.B.; CORSI, M.; CUSATO, S. Respostas morfológicas de Panicum maximum Jacq. cv. tobiatã ao estresse hídrico. Pesquisa Agropecuária Brasileira, v.24, n.7, p.893-898, 1989.

DIAS FILHO, M.B.; SIMÃO NETO, M.B.; SERRÃO, E.A.S. Avaliação da adaptação de acessos de Panicum moximum para a Amazônia Oriental de Brasil. Pasturas tropicales, v.17, n.1, p.3-8, 1995.

ESBROECK, G.A.; HUSSEY, M.A.; SANDERSON, M.A. Leaf appearance rate and final leaf number of switchgrass cultivars. Crop Science, v.37, p.864-870, 1997.

FERRARIS, R.; MAHONY, M.J.; WOOD, J.T. Effect of temperature and solar radiation on the development of dry matter and attributes of elephant grass (Pennisetum purpureum Schum.). Australian Journal of Agricultural Research, v.37, p.621-632, 1986.

FISHER, G.E.J.; DOWDESWELL, A.M. The effects of regrowth and maintenance height on a grass sward with a high density of tillers. Grass and Forage Science, v.51, p.464-468, 1995.

FLORES, E.R.; LACA, E.A.; GRIGGS, T.C.; DEMMENT, M.W. Sward height and vertical morphological differentiation determine cattle bite dimensions. Agronomy Journal. V.85, n.3, p.527-532. 1993. 
FRANK, A.B. \& BAUER, A. Phyllochron differences in wheat, barley, and forages grasses. Crop Science, v.35, n.1 p.19-23, 1995.

FORBES, T.D.A.; COLEMAN, S.W. Forage intake and ingestive behavior of cattle grazing old world bluestems. Agronomy Journal. V.85, n.4, p.808-816. 1993.

FULKERSON, W.J. \& SLACK, K. Leaf number as a criterion for determining defoliation time for Lolium perenne. 1. Effect of water-soluble carbohydrates and senescence. Grass and Forage Science, v.49, p.373-377, 1994.

FULKERSON, W.J. \& SLACK, K. Leaf number as a criterion for determining defoliation time for Lolium perenne. 1. Effect defoliation frequency and height. Grass and Forage Science, v.50, p.16-20, 1995.

GASTAL, F.; BELANGER, G.; LEMAIRE, G. A model of leaf extension rate of tall fescue in response to nitrogen and temperature. Annals of Botany, v.70, p.437$442,1992$.

GAUTIER, H.; VARLET-GRANCHER, C. Regulation of leaf growth of grass by blue light. Physiologia Plantarum, v.98, p.424-430, 1996.

GEORGE, J.R. \& REIGH, G.S. Spring growth and tiller characteristics of switchgrass. Canadian Journal of Plant Science, v.67, p.167-174, 1987.

GILLEN, R.L.; EWING, A.L. Leaf development of native bluestem grasses in relation to degree-day accumulation. Journal of Range Management, v.45, n.2, p.200204, 1992. 
GOMIDE , J.A. O fator tempo e o número de piquetes do pastejo rotacionado. In: SIMPÓSIO SOBRE MANEJO DA PASTAGEM, 14., Piracicaba, 1997. Anais. Piracicaba, FEALQ, 1997. p.253-271.

GOMIDE, C.A. \& GOMIDE, J.A. Morfogênese e análise de crescimento de cultivares de Panicum maximum. In: REUNIÃO ANUAL DA SOCIEDADE BRASILEIRA DE ZOOTECNIA, 33., Fortaleza, 1996, Anais. Fortaleza, SBZ, 1996. p.403-406

GRANT, S.A.; BARTHRAM, G.T.; TORVELL, L. Components of regrowth in grazed and cut Lolium perenne swards. Grass and Forage Science, v.36, p.155-168, 1981.

GRANT, S.A.; BARTHRAM, G.T.; TORVELL, L.; KING, J.; SMITH, H.K. Sward management, lamina turnover and tiller population density in continuously stocked Lolium perenne-dominated swards. Grass and Forage Science, v.38, p.333-344, 1983.

GREENWOOD, D.J.; NEETESON, J.J.; DRAYCOTT, A. Quantitative relationships for the dependence of growth rate of arable crops on their nitrogen content, dry weight and aerial enviroment. Plant and Soil, v.91, p.281-301, 1986.

HAY, R.K.M; WALKER, A.J. An introduction to the physiology of crop yield. Longman Scientific and Technical, 1989. 292p.

HAZARD, L.; GHESQUIĖRE, M.; BARRAUX, C. Genetic variability for leaf development in perennial ryegrass populations. Canadian Journal of Plant Science, v.76, n.1, p.113-118, 1996. 
HESKETH, J.D.; WARRINGTON, L.J. Corn growth response to temperature: rate and duration of leaf emergence. Agronomy Journal, v.81, p.696-701, 1989.

HILLENSHEIM, A. Fatores que afetam o consumo e perdas de capim elefante (Pennisetum purpureum, Schum) sob pastejo. Piracicaba, 1988. Dissertação (M.S.) - Escola Superior de Agricultura "Luiz de Queiroz"/USP.

HODGES, T.; EVANS, D.W. Leaf emergence and leaf duration related to thermal time calculations in ceres-maize. Agronomy Journal, v.84, p.724-730, 1992.

HODGSON, J. Grazing management: Science into practice. 1.ed. Longman Scientific \& Technical, 1990. 203 p.

HOLMES, W. Grass: its production and utilization. 2.ed. Blackwell Scientific Publications, 1994. 306 p.

HUME, D.E. Leaf and tiller production of praire grass (Bromus willdenowii Kunth) and two ryegrass (Lolium) species. Annals of Botany, v.67, p.111-121, 1991.

HUMPHRIES, E.C. \& WHEELER, A.W. The physiology of leaf growth. Annual Review of Plant Physiology, v.14, p.385-405, 1963.

INGESTAD, T. Nitrogen stress in birch seedlings. 2. N, K, P, Ca, and Mg nutrition. Physiologia Plantarum, v.45, p.149-157, 1979.

INGESTAD, T. Nutrition and growth of birch and grey alder seedlings in low conductivity solutions and at varied relative rates of nutrient addition. Physiologia Plantarum, v.52, p.454-466, 1981. 
JANK, L. Melhoramento e seleção de variedades de Panicum maximum . In: SIMPÓSIO SOBRE MANEJO DA PASTAGEM, 12., Piracicaba, 1995. Anais. Piracicaba, FEALQ, 1995. p.21-58.

JANK, L.; SAVIDAN, Y.; SOUZA, M.T.; COSTA, J.G.C. Avaliação do germoplasma de Panicum maximum introduzido da África. 1. Produção forrageira. Revista da Sociedade Brasileira de Zootecnia, v.23, n.3, p.433-440, 1994.

JONES, M.B.; COLLET, B.; BROWN, S. Sward growth under cutting and continuous stocking management: sward canopy structure, tiller density and leaf turnover. Grass and Forage Science, v.37, p.67-73, 1982.

KEMP, D.R.; EAGLES, C.F.; HUMPHREYS, M. O. Leaf growth and apex development of perennial ryegrass during winter and spring. Annals of Botany, v.63, p.349-355, 1989.

KING, J.; GRANT, S.A.; TORVELL, L.; SIM, E.M. Growth rate, senescence and photosynthesis of ryegrass swards cut to maintain a range of values for leaf area index. Grass and Forage Science, v.39, p.371-380, 1984.

KING, R.K.; HILL, M.J.; WILLMS, W.D. Growth response of Festuca altaica, Festuca hallii, and Festuca campestris to temperature. Canadian Journal of Botany, v.73, p.1074-1080, 1995.

LAIDLAW, A.S. \& STEEN, R.W.J. Turnover of grass laminae and white clover leaves in mixed swards continuously grazed with steers at a high and low $\mathrm{N}$ fertilizer level. Grass and Forage Science, v.44, p.249-258, 1989. 
LALONDE, L. \& DHINDSA, R.S. Altered protein synthesis during in situ oat leaf senescence. Physiologia Plantarum, v.80, p.619-623, 1990.

LEMAIRE, G. \& CHAPMAN, D. Tissue flows in grazed plant communities. In: HODGSON, J. \& ILLIUS, A.W. (Ed.) The ecology and management of grazing systems 1.ed. CAB International, 1996. cap.1, p.3-36.

MacADAM, J.W.; VOLENEC, J.J.; NELSON, C.J. Effects of nitrogen on mesophyll cell division and epidermal cell elongation in tall fescue leaf blades. Plant Physiology, v.89, p.549-556, 1989.

MATTHEW, C.; LEMAIRE, G.; HAMILTON, N.R.S.; GARAY, A.H. A model selfthinning equation to describe size/density relationships for defoliated swards. Annals of Botany, v.76, p.579-587, 1995.

MAZZANTI, A.; LEMAIRE, G.; GASTAL, F. The effect of nitrogen fertilization upon the herbage production of tall fescue swards continuously grazed with sheep. 1 . Herbage growth dynamics. Grass and Forage Science, v.49, p.111-120, 1994.

MEIRI, A.; SILK, W.K.; LAÜCHLI, A. Growth and deposition of inorganic nutrient elements in developing leaves of Zea mays L. Plant Physiology, v.99, p.972-978, 1992.

MILTHORPE, F.L. \& MOORBY, J. An introduction to crop physiology. Cambridge University Press. cap.7, p.124-139. 1974. 
MUCHOW, R.C. \& CARBERRY, P.S. Environmental control of phenology and leaf growth in a tropically adapted maize. Field Crops Research, v.20, p.221-236, 1989.

MUCHOW, R.C. \& CARBERRY, P.S. Phenology and leaf-area development in a tropical grain sorghum. Field Crops Research, v.23, p.221-237, 1990.

NOODÉN, L.D.; HILLSBERG, W.; SCHNEIDER, M.J. Induction of leaf senescence in Arabidopsis thaliana by long days through a light-dosage effect. Physiologia Plantarum, v.96, p.491-495, 1996.

FARFITT, R.L.; JOE, E.N.; COOK, F.J. Water use and pasture growth on judgeford silt loam. New Zealand Journal of Agricultural Research, v.28, p.387-392, $1985 a$.

PARFITT, R.L.; ROBERTS, A.H.C.; COOK, F.J. Water use, irrigation, and pasture production on stratford silt loam. New Zealand Journal of Agricultural Research, v.28, p.393-401, 1985b.

PARSONS, A.J.; JOHNSON, J.R.; HARVEY, A. Use of a model to optimize the interaction between frequency and severity of intermittent defoliation and to provide a fundamental comparison of the continuous and intermittent defoliation of grass. Grass and Forage Science, v.43, p.49-59, 1988.

PARSONS, A.J.; LEAFE, E.L.; COLLETT, B.; PENNING, P.D.; LEWIS, J. The physiology of grass production under grazing. II. Photosynthesis, crop growth and animal intake of continuously grazed swards. Journal of Applied Ecology, v.20, p.127-139, 1983. 
PARSONS, A.J. \& PENNING, P.D. The effect of duration of regrowth on photosynthesis, leaf death and the average rate of growth in a rotationally grazed sward. Grass and Forage Science, v.43, p.15-27, 1988.

PEARSE, P.J. \& WILMAN, D. Effects of applied nitrogen on grass leaf initiation, development and deaf in field swards. Journal of Agricultural Science, v.103, p.405-413, 1984.

PINTO, J.C.; GOMIDE, J.A.; MAESTRI, M. Produção de matéria seca e relação folha:caule de gramíneas forrageiras tropicais, cultivadas em vasos, com duas doses de nitrogênio. Revista da Sociedade Brasileira de Zootecnia, v.23, n.3, p.433-440, 1994.

POPPI, D.P.; MINSON, D.J.; TERNOUTH, J.H. Studies of cattle and sheep eating leaf and stem fractions of grasses. I. The voluntary intake, digestibility and retention time in the reticulo-rumen. . Australian Journal of Agricultural Research, v.32, p.99-108. 1981.

RAWSON, H.M. Rapid leaf growth in wheat and its links with flowering. Australian Journal of Plant Physiology, v.18, p. 109-119, 1991.

RICHARDS, J.H.; MUELLER, R.J.; MOTT, J.J. Tillering in tussock grasses in relation to defoliation and apical bud removal. Annals of Botany, v.62, p.173-179, 1988.

SAlisburY, F.B. \& ROSS, C.W. Plant Physiology. 4.ed. Wadsworth Publishing Company, 1992. 682 p. 
S.A.S. Institute, Inc. SAS User's guide:Statistics. CARY, N.C. (Ed.), 1986.

SAVIDAN, Y.H.; JANK, L.; COSTA, J.C.G. Registro de 25 acessos selecionados de Panicum maximum, Campo Grande, EMBRAPA-CNPGC, 1990. 68p. (EMBRAPA-CNPGC, Documentos, 44).

SEEMANN, J.R.; THOMAS, D.S.; WANG, J.; OSMOND, B. Environmental effects on photosynthesis, nitrogen-use efficiency, and metabolite pools in leaves of sun and shade. Plant physiology, v.84, p.796-802, 1987.

SINGH, D.K. Effects of cutting management on yield and quality of different selections of guinea grass (Panicum maximum, Jacq.) in a humid subtropical environment. Tropical Agriculture, v.72, n.3, p.181-187, 1995.

STAPLETON, J. \& JONES, M.B. Effects of vernalization on the subsequent rates of leaf extension and photosynthesis of perennial ryegrass (Lolium perenne L.) Grass and Forage Science, v.42, p.27-31, 1987.

TALLOWIN, J.R.B.; WILLIAMS, J.H.H.; KIRKHAM, F.W. Some consequences of imposing different continuous-grazing pressures in the spring on tiller demography and leaf growth. Journal of Agricultural Science, v.112, p.115-122, 1989.

THOMAS, H. Terminology and definitions in studies of grassland plants. Grass and Forage Science, v.35, p.13-23, 1980.

THOMAS, $\mathrm{H}$. Accumulation and consumption of solutes in swards of Lolium perenne during drought and after rewatering. New Phytologist, v.118, p.35-48, 1991. 
THOMAS, H. \& STODDART, J.L. Leaf senescence. Annual Review of Plant Physiology, v.31, p.83-111, 1980.

UNRUH, J.B.; GAUSSION, R.E.; WIEST, S.C. Basal growth temperature and growth rate constants of warm-season turfgrass species. Crop Science, v.36, p.997-999, 1996.

VINE, D.A. Sward structure changes within a perennial ryegrass sward: leaf appearance and death. Grass and Forage Science, v.38, p.231-242, 1983.

VOLENEC, J.J. \& NELSON, C.J. Responses of tall fescue leaf meristems to N fertilization and harvest frequency. Crop Science, v.23, p.720-724, 1983.

WILHELM, W.W \& McMASTER, G.S. Importance of the phyllochron in studying development and growth in grasses. Crop Science, v.35, n.1, p.1-3, 1995.

WILMAN, D. \& MARES MARTINS, V.M. Senescence and death of herbage during periods of regrowth in ryegrass and red and white clover, and the effect of applied nitrogen. Journal of Applied Ecology, v.14, p.615-620, 1977.

WILMAN, D. \& MOHAMED, A.A. Early spring and late autumn response to applied nitrogen in four grasses. Journal of Agricultural Science, v.94, p.443-453, 1980.

WILSON, J.R. Variation of leaf characteristics with level of insertion on a grass tiller. 1. Development rate, chemical composition and dry matter digestibility. Australian Journal of Agricultural Research, v.27, p.343-354, 1976. 
WOLEDGE, J. The effect of shading on the photosynthetic rate and longevity of grass leaves. Annals of Botany, v.36, p.551-561, 1972.

WOLFE, D.W.; HENDERSON, D.W.; HSIAO, T.C.; ALVINO, A. Interactive water and nitrogen effects on senescence of maize. I. Leaf area duration, nitrogen distribution, and yield. Agronomy Journal, v.80, p.859-864, 1988a.

WOLFE, D.W.; HENDERSON, D.W.; HSIAO, T.C.; ALVINO, A. Interactive water and nitrogen effects on senescence of maize. II. Photosynthetic decline and longevity of individual leaves. Agronomy Journal, v.80, p.865-870, 1988b. 